University of Louisville

ThinkIR: The University of Louisville's Institutional Repository

Electronic Theses and Dissertations

8-2015

\title{
The love that refuses to speak its name : examining queerbaiting and fan-producer interactions in fan cultures.
}

Cassandra M. Collier,

University of Louisville

Follow this and additional works at: https://ir.library.louisville.edu/etd

Part of the Feminist, Gender, and Sexuality Studies Commons

\section{Recommended Citation}

Collier, Cassandra M., "The love that refuses to speak its name : examining queerbaiting and fan-producer interactions in fan cultures." (2015). Electronic Theses and Dissertations. Paper 2204.

https://doi.org/10.18297/etd/2204

This Master's Thesis is brought to you for free and open access by ThinkIR: The University of Louisville's Institutional Repository. It has been accepted for inclusion in Electronic Theses and Dissertations by an authorized administrator of ThinkIR: The University of Louisville's Institutional Repository. This title appears here courtesy of the author, who has retained all other copyrights. For more information, please contact thinkir@louisville.edu. 
THE LOVE THAT REFUSES TO SPEAK ITS NAME:

EXAMINING QUEERBAITING AND FAN-PRODUCER INTERACTIONS IN FAN CULTURES

\author{
By \\ Cassandra M Collier \\ B.A., Bowling Green State University, 2012 \\ A Thesis \\ Submitted to the Faculty of the \\ College of Arts and Sciences of the University of Louisville \\ in Partial Fulfillment of the Requirements \\ for the Degree of \\ Master of Arts \\ in Women's and Gender Studies \\ Department of Women's and Gender Studies \\ University of Louisville \\ Louisville, Kentucky
}

August 2015 

THE LOVE THAT REFUSES TO SPEAK ITS NAME:

EXAMINING QUEERBAITING AND FAN-PRODUCER INTERACTIONS IN FAN CULTURES

By

Cassandra M Collier

B.A., Bowling Green State University, 2012

A Thesis Approved on

May 27, 2015

by the following Thesis Committee:

Dr, Dawn Heinecken

Dr, Diane Pecknold

Dr. Gul Marshall 


\section{DEDICATION}

For my mom, who had watched countless shows with me, driven me to conventions, and has always supported my geeky hobbies. 


\section{ACKNOWLEDGEMENTS}

I'm deeply grateful for my advisor, Dr. Dawn Heinecken. Without her patience, encouragement and invaluable feedback, this would be a very different document and I'm thankful for her guidance. I appreciate my fabulous cohort, Sarah, Leasha, Yasmeen, Laurel, and Patrick, who listened to this project many, many times, and always offered support and feedback. I'm grateful for my family, who has supported me throughout my education. I'm would not have been able to complete this without Steven, Josh, Daniel, Stephen, and Amanda, who read this project repeatedly at various stages and watched countless hours of detectives and hunters with me. I am also thankful for the unending support of my sorors, particularly Charisse and Kaitlin. 


\begin{abstract}
THE LOVE THAT REFUSES TO SPEAK ITS NAME:

EXAMINING QUEERBAITING AND FAN-PRODUCER INTERACTIONS IN FAN CULTURES

Cassandra M. Collier
\end{abstract}

May $27^{\text {th }}, 2015$

In this thesis, I focus on questions of fan power, resistance, and producer interaction, particularly around the issue of sexuality. I examine the fan cultures surrounding Supernatural and Sherlock, constructing two case studies. Each case study examines the text of the shows, the producer-fan relationship and the fan reworkings of the text, specifically fanfiction. This approach allows for an analysis situated firmly within the world of the fan. By situating my work against the larger conversation regarding resistance and power in fan studies, I work to further trouble the characterization of fan spaces as resistant. Additionally, I trace the different communication styles used by producers and examine what types of fan efforts are sanctioned. My research demonstrates that Supernatural and Sherlock are encoded with homoerotic subtext and have used conventional slash tropes and interpretations to do so, as well as exploring the vastly different ways fan cultures have developed 


\section{TABLE OF CONTENTS}

ACKNOWLEDGEMENTS.................................................................................................... iv

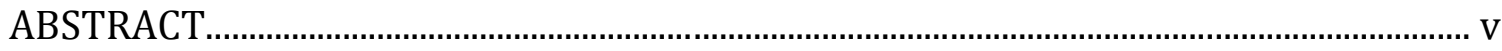

INTRODUCTION

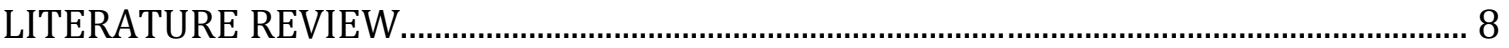

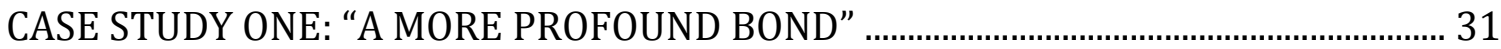

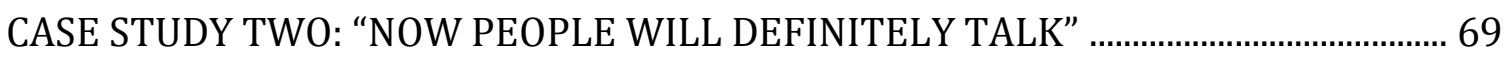

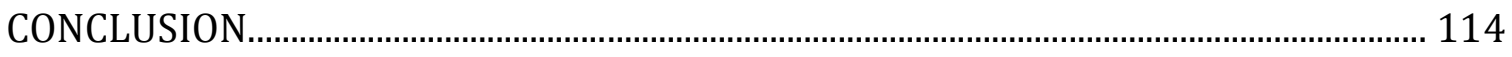

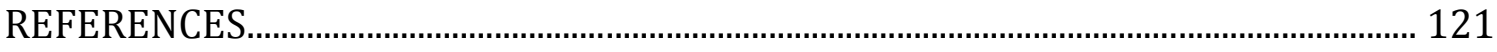

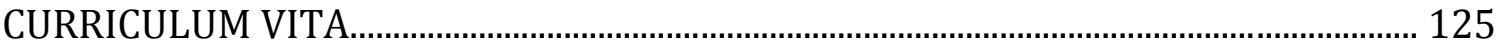




\section{TALKING BACK AND BACK-TALK: FANDOM IN THE DIGITAL AGE}

Ever since Henry Jenkins' Textual Poachers was published in 1992, there has been a growing section of academia devoted to fan studies and fan activities such as fan fiction, fans' practice of writing stories about the characters in their favorite series. A particular area of focus has been slash, a type of fan fiction that features gay cisgender (biological sex matches gender identity) male romantic pairings. Slash fans "ship," (derived from the word relationship) these characters together. It is not uncommon to see slash stories featuring 'deviant' sexuality, where a multitude of kinks and fetishes are all considered and enacted by the characters (Reid). Slash can be seen as one way fans attempt to impose their own narrative and worldview on a text and it has been characterized as resistant, a means of pushing back against dominant cultural ideologies (Dhaenens, Van Bauwel and Biltereyst 344), a disruption to hegemonic masculinity, and a place to explore egalitarian relationship dynamics (Cicioni; Jenkins; Woledge),

The fan practice of shipping can be seen as leading to more gay-friendly images on TV, especially when the producers are willing to engage with their fans' queer narratives. Producers are increasingly seeking to court fans through queerbaiting, a practice in which they give either in-show nods to fandom or incorporate into the canon common themes found in fan activities like slash. Queerbaiting is usually done in hopes of expanding the audience for the show, attracting slash fans and LGBTQ folk while allowing producers to refrain from 
isolating viewers who would be alienated by the depiction of openly LGBTQ characters. Queerbaiting often relies on subtext and narrative techniques to code characters as potentially queer to viewers 'in the know,' allowing queer viewers a space to identify themselves within the show without needing to make an explicit statement regarding the issue. The text becomes "intentionally [coded] with at least two 'preferred readings': one for bisexual, lesbian, and/or gay readers, and one for heterosexual readers" (Sender 305). This, however, is a move that denies queers real visibility, preserving the status quo and enabling producers to pay lip service in support of ideas like equality.

Queerbaiting is thus connected to homonormative ideology. Lisa Duggan coins the concept of homonormativity in her book, The Twilight of Equality? Neoliberalism, Cultural Politics, and the Attack on Democracy. In the book, Duggan describes the cultural politics of neoliberalism, as a contradictory politic that incorporates conflicting views in an effort to garner the most support. For instance, it idealizes the private sphere and views government efforts in the public sector as intrusive, while government assistance to the private sector is perfectly fine (49). The new homonormative order, as she terms it, is "a politics that does not contest dominant heteronormative assumptions and institutions, but upholds and sustains them while promising the possibility of a demobilized gay constituency and a privatized, depoliticized gay culture anchored in domesticity and consumption" (50). She further explains homonormativity as a means for establishmentsanctioned voices (the Independent Gay Forum in Duggan's example) to bring a "desired public" from the margins to the mainstream. Mainstreaming is achieved 
through strategies like repositioning equality in assimilationist terms, such as gay marriage, increasing commercialization/corporate sponsorship, and patriotism (51). These moves are designed to "shrink gay spheres," and "redefine gay equality... as access to institutions of public privacy" (51). Achieving equality means being able to be married, participate in the military, and have major corporations sponsor LGBTQ organizations or events such as Pride. Substantial critique of these hegemonic institutions is displaced as we instead seek to become a part of them. This mainstreaming dilutes much of the initial gay politics that called for sexual liberation and eradication of traditional constructions of gender.

As producers seek to cultivate fans for their properties through strategies such as queerbaiting, fandom and fan activities are becoming more entangled within capitalism and commodification. In the digital age, there have never been more opportunities for fans to engage with their favorite show and each other. Fandom is creeping more and more into the public eye. Networks, production staff, and PR people connect to us through multiple platforms, such as Facebook, Twitter, Tumblr and Instagram, encouraging marathon viewing, contest participation and real-time dialogue about the latest developments in TV shows, and easing everyday viewers into fandom. People are constantly encouraged to be aware of television and to reach out to talk about it with others (The Nielsen Company).

Fans enjoy communication with the cast and crew of their favorite shows at unprecedented levels. They are able to communicate at any moment with actors, writers, and producers, and are no longer limited to moderated panels at 
conventions happening at scheduled times. This fan involvement can raise the show's profile on the internet (its website, Facebook, Twitter, Instagram, Tumblr, Vine) which many of the show staff hope translate to increased ratings. The strict boundaries between producers and fans are becoming blurred, as fans like Steven Moffat gain institutional authority as media producers and social media allows a greater dialogue between fans and producers. Fans' unprecedented level of access to show staff through social media has enabled the practice of fan activism, or as Derek Johnson describes it, "fan-tagonism" (Johnson 291), where fans directly lobby the staff to advocate for their vision to be made into canon (the primary text of the show).

This new dynamic between fans and producers raises questions of power not often addressed in scholarly literature on fandom: who are the empowered entities in this relationship- the fans who are being courted to ensure the show's survival or the producers who control the narrative? Fan activism, in this case where fans are advocating for particular show developments, happens in a world that not only includes the canonical text of the show, but the extra-textual word of the producers, who are increasingly communicating with fans and constructing hyperdiegetic worlds with which fans interact. I'm interested in how fan culture expresses itself in response to the queerbaiting strategies in both the text and hyperdiegetic text/producer actions, as these are entwined and become a part of fandom. How do producers structure the representation of sexuality in their texts in ways that appeal to fans? How do producers and fans communicate about the "queer" content of their shows? Are fan and producer values different when it comes to the text and 
interpretation of meaning? How much power do fans really have, even in the age of social media, to resist and insist on their own readings of the shows?

My project examines the fan cultures of Supernatural and Sherlock, including the texts of each show; the interaction of fans with those with "producerly authority," such as writers and actors, and fan writings. A major goal is to determine the type of producer-fan relationship they enact and the role these relationships may play in how the fandom reproduces or resists homonormativity (Johnson). I show that while some fans accept producers' authority and queerbaiting strategies and replicate homonormative ideology in their own writings, other fans have a more antagonistic relationship with producers and resist producer authority and their queerbaiting practices.

This project takes the form of two case studies, where I utilize multiple sites of analysis. I provide a textual analysis of BBC's Sherlock and the CW's Supernatural to examine how producers have encoded a homoerotic subtext, intentionally queerbaiting to broaden viewership. I read these against conversations between fans and producers regarding the characters' queer potential and the topic of slash shipping. In regards to Supernatural, I show that the producers have developed a collaborative relationship with fans, in which fans often favor a dialogue with producers rather than performing an overt critique of the show. In contrast Sherlock is an example of when fan shipping activity is resolutely dismissed by the show's staff, and fan criticism of the show's plot and tactics remains lively. Because fanfiction is another venue in which fans can resist producerly authority, I then examine the fanfiction of each fandom. 
Some Supernatural fans, who share a more collaborative relationship with producers, create stories and art that compromise on more extreme aspects of sexuality to create a ship that is palatable to the show's staff and mainstream audiences, enacting the sexual politics of homonormativity in the process. I argue that the Supernatural fandom is not a subversive site of resistance to heteronormativity, as slash has been characterized at times in scholarship, but rather has strong tendencies that encourage a homonormative ideology. In contrast, Sherlock fans' adversarial relationship with the show runner, Steven Moffat (Pantozzi; Smith) coincides with fans' creation of stories that escape the cycle of increasing homonormativity and continue to resist dominant constructions of sexuality.

I do not intend to argue that particular producer messages or practices are the causes of the difference between these fan spaces. Such a causal argument is beyond the scope of this project. Instead, I hope to examine the different kinds of fan cultures produced in the new media environment in which producers court fans via queerbaiting and other practices and to speculate on why different fan cultures produce different forms of slash. As part of this examination, I demonstrate the different ways producers attempt to appeal to fans, the different styles in which producers and fans interact as well as the distinct forms of slash different communities of fans create.

Previous work has isolated different aspects of fandom, focusing either solely on fanfiction, or on the fan-producer interaction. I believe with a more holistic perspective, more work can be done to understand how these various spheres of 
fandom interact and affect each other. By focusing specifically on issues of sexuality, power, and resistance, I believe my work allows for a new perspective to be applied to the producer-fan dialogue. I situate this project in the larger context of fandom as fans experience it, which includes interacting with the show, fan works and the producer interactions. 


\section{LITERATURE REVIEW}

Slash-fan-constructed stories about the romantic same-sex relationship between two male characters-has been a popular topic of investigation for nearly twenty years. Often, fan activity, such as slash, is described as resistant and subversive to hegemonic masculinity and heteronormativity (Jenkins, Reid, Cicioni), although there are notable exceptions that discuss slash's limitations (Hunting, Åström). In this chapter, I detail how slash has been traditionally constructed as resistant, and alternatively as normalizing. In addition, recognizing the increasing scope of fandom in the new media age, I expand my review to include an examination of the fan-producer interaction, the different kinds of relationships that may develop between the two, and how fans' "affirmational" or "transformational" status may affect their fan fiction's transgressive potential.

\section{Fans and fan activity}

Slash fans write about the experiences of men in same-sex relationships, very far removed from the lived experience of most slash fans, who are gendered as female and are largely heterosexual. In the introduction of Textual Poachers, Henry Jenkins, describes fans as "largely female, largely white, largely middle-class" (1). Jenkins traces the history of the word "fan." He notes that while 'fan' was first used 
as an abbreviation to describe male followers of sporting events, the word expanded to other arenas, with one of the "earliest uses" in reference to "women theatergoers, 'Matinee Girls,' who male critics claimed had come to admire the actors rather than the plays" (Jenkins 12). This feminine gendering of fandom, from the "Matinee Girls' to the screaming teenager or the groupie, demonstrates a long history of identifying heterosexual desire as a motivator for female fan identity. While male fans are characterized as awkward or obsessed (Jenkins invokes the media stereotype of the "Trekkie"), the female fan is implied in mainstream culture to be interested only in the physicality of the male actors, rather than the story or narrative of the creative work. This construction has served as one way mainstream discourse discounts female fan activities.

However, in many academic studies female identity is seen as central to the resistant qualities of fan activities. For example, Star Trek fans were among the most visible of early media fandoms and the community was a place where women's narratives flourished. Camille Bacon-Smith cites the incredible numbers of female fans who crafted reams of original work based on the show they enjoyed so much. From fanfiction to graphic art, from criticism to songs, Bacon-Smith estimates, "women have accounted for over $90 \%$ of the writing and graphic arts, and for almost all the editing of... fan publications" ("Spock among the Women" 1). In contrast, the more popular fan involvement for males is in the form of costuming (cosplay), crafts, or gaming rooms at conventions (Bacon-Smith "Spock among the Women"). She suggests that the legal restrictions that bar fanfiction creators from profiting from their labor are a reason that women are more likely to contribute to 
written works or art. Bacon-Smith argues that since women are used to working in isolation for "little or no pay, [they] bring a different set of motivations to their writing and art" ("Spock among the Women" 1). Rather than making money, women want to talk to other women. Prioritizing a shared fantasy universe over original creations, the commonality of source material allows the women to engage in discussion of "real-life concerns such as sexuality and equality... [through] the metaphorical language of Star Trek," (Bacon-Smith "Spock among the Women" 1). Bacon-Smith says exploration of these themes of sexuality and equality through narrative allows enough distance for women to critically engage and provides a safe context to discuss these ideas. Bacon-Smith showcases a significant portion of fan activity as gendered, revealing of women's gendered relationship to media texts and to larger cultural discourses of sexuality and desire.

\section{Conceptualizing Slash}

While fanfiction has been a part of the fan experience for quite some time, slash fanfiction is believed to have debuted in the Star Trek fandom, with the pairing between Captain James T. Kirk and Spock, commonly referred to as K/S. However, there are other early notable pairings in other titles, such as Benton Fraser and Ray Vecchio, styled as RayK/Fraser, from the show Due South, and the title characters of Starsky and Hutch. More recently, popular pairings include Steve Rogers and James "Bucky" Barnes, often written as "Stucky," from the current Marvel Cinematic Universe, as well as Dean Winchester and Castiel ("Destiel") from Supernatural, and Sherlock Holmes and John Watson ("Johnlock") from the BBC's Sherlock. Slash shipping has moved from cult television shows and movies to more popular, 
mainstream titles as fans are increasingly being sought after and cultivated as audience members (Hills 36). Producers are increasingly aware of traditional fan activities, such as slash and shipping, as fans become producers and fan spaces are mined for their PR potential.

Bacon-Smith links the popularity of slash among female fans to the lack of women in series to whom fans can relate, especially given that in visual culture images and representations are frequently male-controlled (Enterprising Women: Television Fandom and the Creation of Popular Myth 241). She also infers, more cruelly, that the women who participate in slash do so because of their single relationship status, or their physical attributes such as being overweight or unattractive (Enterprising Women: Television Fandom and the Creation of Popular Myth 247). Ultimately, Bacon-Smith argues “women don't write erotic fiction for political reasons," painting slash as simply a means of sexual gratification for the women involved (Enterprising Women: Television Fandom and the Creation of Popular Myth 247). Bacon-Smith's analysis draws on a long history of reducing female fandom to sexual desire, an outlook that limits the agency and creativity of female fans, and shuts down any possibilities for alternative interpretation.

In contrast, Jenkins offers a very different analysis of the genre. He forwards that slash allows writers to explore the subtexts they see within the text of the canonical material and engage in a fuller analysis of characters and performance. He argues that slash encourages a deeper investigation into masculinity outside the damaging patriarchal constraints in which it usually operates (Jenkins 202-05). Bacon-Smith points out that one reason women read an intimate relationship 
between two male protagonists is simply because it exists (234). Drawing on the history of the homosocial partnership in Western culture, she reminds us of the rich tradition of devoted male friendship. When the series creators invoke deep male friendship, slash fans develop an "expectation of content," reading a romantic subtext that "the author [did] not include or intend" (236). Similarly, Jenkins connects fan interpretations of the erotic potential of deep male friendship and the long history of male homosocial desire chronicled by Eve Kosofsky Sedgewick (Jenkins). Sedgewick created the phrase "male homosocial desire" as a means to "hypothesize the potential unbrokenness of a continuum between homosocial and homosexual" (Sedgwick 696). Despite the long historical tradition of male bonds and male love, she saw this continuum as one that was no longer compatible with performing hegemonic masculinity in society. The homosocial continuum provides a means of circumventing societally enforced "obligatory heterosexuality" in favor of a more fluid bond between men (Sedgwick 3). Female fans, usually operating in a Western context, will be familiar with this long history of male camaraderie. When faced with it in popular narratives, many will find it easy to pick up on the trope and add in their own "expectation of content," and further develop the intimacy between the characters (Bacon-Smith 236).

Members of the slash community share particular interpretive strategies to produce a reading of a same-sex relationship. Camille Bacon-Smith notes that to participate in the slash community, she had to "develop an understanding of the dense links between visual images perceived as carrying erotic content on the screen and the community's own literary codes of romantic homoeroticism" (Bacon- 
Smith Enterprising Women: Television Fandom and the Creation of Popular Myth 231). Fans who engage with slash often draw heavily on the images presented through the canon of series, ascribing a particular meaning to storytelling tactics and how the actors chose to convey a line. For example, eye contact between characters or the necessity of close-ups or a small space between the actors to shoot for television screens is interpreted as a sign of emotional intensity and intimacy, even if the show had previously "established [a] friendly relationship" between the two male characters (Bacon-Smith Enterprising Women: Television Fandom and the Creation of Popular Myth 232). Or, in Star Trek fandom, the mind meld becomes a metaphor for sexual intimacy, frequently marking a milestone in the course of a sexual relationship between Kirk and Spock (Bacon-Smith Enterprising Women: Television Fandom and the Creation of Popular Myth). These codes are so pervasive in slash works that when they are depicted within the canon of the show, they become imbued with the meanings established by the fans. When actions that are coded as particularly significant within slash fanfiction that appear within the episodes, such as the Vulcan mind meld in Star Trek or the mentioning of the "profound bond" in Supernatural, they validate fans' interpretation of same-sex desire. Slash fans utilize the bonds expressed between male characters to change the script on masculine norms. Their stories enact a form of gender blending that allows men the "emotional responsibility" of relationships, in contrast to the stereotypical division of duties in a heterosexual relationship (Green, Jenkins and Jenkins 17-19).

\section{Slash as subversive}


Because slash readings do not mesh with intended messages of producers, Jenkins views slash as representing "a particularly dramatic break with the ideological norms of the broadcast material," a site that bucks the hegemonic expressions of masculinity and heteronormativity traditionally found in popular media (Jenkins 221). His view of slash as a resistant space where women can explore sexuality and expression has been accepted and incorporated in most current analyses of slash. For example, Green et al view slash as a means of "rewriting masculinity," allowing female slash writers to create male characters that don't fall into hegemonic scripts of masculinity, and feature characters who can freely explore intimacy and emotions of friendship and love that are typically silenced. This perspective is echoed by María del Mar Rubio-Hernández, who views slash as "questioning the traditional concepts of gender" (541). Hernández views slash as "[reversing] the prevailing male role," allowing male characters to be "portrayed as more sensitive and emotional" (541).

Mirna Cicioni writes about slash's "subversive potential," positioning slash as a space to allow women to voice critiques of hegemonic society and its expectations in a relatively non-threatening manner. Cicioni sees slash typically as a progressive space because of the common ground it gives its writers and audience to talk about or explore issues of power in heterosexual relationships or women's desire. Specifically, Cicioni argues that slash serves as a site of fantasy romance that allows for an egalitarian relationship between partners (169). However, because egalitarianism is present only between gay male couples, rather than heterosexual couples, slash "reveals a pessimistic unease about the institution of heterosexuality; 
this is despite the majority of writers and readers of slash text being committed to heterosexuality in their own lives" (Cicioni 169). Slash thus enables writers to express discontent with their own heterosexual situation, giving them time and space to work through their own thoughts.

Susanne Jung argues that slash "tackle[s] not only the primary binarism of homo/heterosexual definition, but also other binarisms influenced by that dichotomy such as knowledge/ignorance, masculine/feminine, high/low cultures of writing" (Jung para 5). Slash is revolutionary in its portrayal of masculinity, as well as its very status as a predominantly female genre. Slash, with its propensity for the erotic and the sexually explicit, disrupts what are traditionally coded as "feminine," genres. It blends the "emotional satisfaction" believed to be found in romance novels, and the "masculine" preference for pornography into a "genre which includes sexually explicit scenes, but also one in which the sex scenes fulfill narrative functions," resisting being wholly romance or pornography and thereby challenging the masculine/feminine binary of writing and genre enjoyment between romance and pornography (Jung para 27). Narrative functions, like character development or advancing the plot are equally as important as the erotic moments in slash, creating what Jung calls a "revolutionary 'female pornography'” (para 27). Jung views slash fans and writers as performing a "communal and grass roots critique not only of popular culture but also of heterosexual hegemonic notions of gender and sexuality" (Jung para 5).

Slash provides a space for writers to work through issues of misogyny and homophobia. In their ethnographic work, Green et al found that slash writers, 
mostly female, often reflected on the scarcity of female characters, the lack of female-centered relationships, and the minor support roles to which women are often relegated in the television shows. They also found a population of fan writers who view slash as deliberately political, and who criticize homophobic slash factions who describe characters as "not really gay" (23). These fan writers challenge heteronormativity by discussing the need for a more plainly stated queer identity for characters in slash (Green, Jenkins and Jenkins 22-23).

Some argue that slash fans examine "queerness, the social construction of gender, and the politics of sexuality," and view fan activity as a subversive resistance to hegemonic culture (Dhaenens, Van Bauwel and Biltereyst 343). Frederik Dhaenens, Sofie Van Bauwel, and Daniel Biltereyst point to the need to explore fans' active queering strategies. Queer theory emphasizes moving away from universal categories of identity like gay or woman and utilizes Foucault's ideas on power and resistance (338). Foucault believed that power and knowledge are heavily intertwined, that knowledge is a form of control, and power generates new forms of knowledge. However, there is always a possibility of resistance to power. Queer theory resists a binary between gay and straight and instead posits queerness as "a category of knowledge that encompasses the possibility of imagining homosexuality at the center of popular culture and society, which also exposes the emphasis on heteronormativity" (338). Queer theory encourages the exposure of cultural norms regarding sexuality and identity performance, and creates a space for subversion and resistance to hegemonic culture. 
Reid highlights the queer potential of some forms of fan fiction. She notes that the material that writers cover in dark fics-fanfiction where characters are hurt, mentally, physically, and/or emotionally and the text "[denies] comfort for characters and readers" — can be read as queer practices (468). Such stories engage with a "variety of non-heteronormative sexual practices," and examine characters outside the confines of domestic bliss, exploring "dark and violent behaviors" (473). These narratives subvert slash's status as a "feminine genre" based on "the conventions of romance plots, domestic settings, and the ideal of egalitarian relationships" (467). Reid characterizes dark fic as a "mode," and not a genre. These dark fics are "tragedy minus the catharsis," where writers construct a story that makes no promises of a happily ever after. Reid argues that academic focus should move away from focusing on fanfiction simply because it contains gay characters to interrogating the queer practices that disrupt normativity, such as those found in the dark fic she examines (480).

\section{Slash's limitations}

While many theorists view slash as a resistant space and site of queer practices, others note how it may reinforce hegemonic norms. For example, Elizabeth Woledge notes the ways that fan writers describe male characters with a mix of stereotypically Western masculine and feminine characteristics, blending "masculine descriptors such as 'powerful,' 'superior,' 'rigid' and 'exacting,' with feminine descriptors of 'shorter,' 'subordinate,' and 'bowed in service' (Woledge 54). While this kind of gender blending can be seen as playing with gendered behaviors and descriptors, it still relies on a framework that views gender as solely a binary 
between male and female attributes (62). Woledge also points out that slash frequently draws stereotypical associations of male gay identities with feminine traits, such as using 'pretty' to describe male characters and the correlation of "bottoming" (taking the role of the partner who is penetrated during intercourse) with submissiveness. In addition to relying on a gender binary, gender-blended characters are involved in relationships that mimic heterosexual conventions, where the characters are either the active (penetrating) partner, and thus written to be more masculine, or the passive (penetrated) partner, presented as more feminine within an encounter.

This replication of hegemonic heterosexuality suggests slash is not as much a space of resistance as has been claimed. Similarly, in a case study of the Queer as Folk fandom, Kyra Hunting explores the tendency of fans to soften radical narratives. For example, within Queer as Folk, a sexual encounter doesn't indicate the presence of deeper feelings or the expectation of a relationship between the characters. However, Hunting notes that fanfiction does not follow the source material's attitude regarding sexual freedom. Instead, she found that fan writers often "develop their own rules for a relationship that privileges monogamy and traditional romance" (5.2). In addition to this push towards "acceptable" depictions of sexuality, Hunting notes that these stories generally tap into a script that promotes a "traditional" family, and the intimacy that can come from a monogamous relationship, ignoring the canon that showed coupled characters engaging in threesomes or other sexually "open" behavior (5.4). Fans can "impose a romance 
narrative and... its heteronormative trappings" even when the canon itself resists these structures (6.1).

Even stories in which fans deliberately disrupt the script of gendered bodies by exploring the idea of mpreg (male pregnancies) fail to be radical. Berit Åström examines the use of mpreg in Supernatural fan fictions. Even though Åström investigates stories centering on two brothers who are sexually intimate and capable of conception, she notes that most of the fanfictions "still draw on traditional constructions of gender in the family," enforcing traditional gender roles for the children conceived, and the repeated insistence that Sam and Dean, despite being gay, are not effeminate (6.3). The men are expected to uphold and perform hegemonic masculinity, and the girl they raise is notably enforced to performing femininity, as opposed to joining in the active masculinity of her fathers and brothers. These writers demonstrate how fanfiction can enact homonormative ideology.

\section{The producer and fan dialogue}

It wasn't long ago that the only ways to reach a show's staff were to write to a studio in the hopes of receiving a form letter typed by a secretary, or directly at conventions, which were restricted in terms of time and geography. Over social media, fans are able to reach out to a show's actors, writers, and producers at any time convenient to them. Some writers, such as Shonda Rimes, have embraced this accessibility, freely tweeting and engaging with fans throughout the week and during the airing of a new episode. In Spreadable Media, Henry Jenkins, Sam Ford and Joshua Green discuss television's shift to an "engagement-based paradigm" 
(116). Here, Jenkins, Ford, and Green highlight the value of transmedia engagement, or utilizing multiple platforms to deliver content to fans, with each outlet "becoming new sources of revenue and each further fueling audience fascination" (134). Transmedia engagement is a "win/win" experience, generating more profits to producers and helping to cultivate audiences while simultaneously providing more content for fans to enjoy. With the potential offered by social media, fans are able to communicate much more easily with producers, including making clear their expectations of producers. In her research on soap opera fans, Rebecca Williams notes that fans expect producers "to provide character continuity and consistency... and the show's narrative history to be respected and adhered to" (285). Fans apply to the producers themselves to argue for their own standards of storytelling, expecting the producers to share their dedication to and respect for the canon,

Rekha Sharma shows the collaborative nature of fan-producer communications. In her examination of Community, Sharma argues that the "proliferation of interactive communication technologies and the removal of barriers to entry to mass communication have rendered the roles of creator and consumer more interchangeable than they have ever been" (195). Sharma details the active relationship between the series creator Dan Harmon and the fans on social media, which allow for a "collaborative interpretation" that incorporates fan discussions and interpretations into the canon of the show (186). Sharma's study of Community finds a producer-fan relationship in which producers and fans are each openly influenced by one another, and act as collaborators in their mutual appreciation for the show. Creators solicit feedback from fans and fans can see 
implementation of their suggestions, from small things like naming a monkey to an incorporation of a fan video into the canon. Sharma writes that "Whereas fans have previously been acknowledged to be active consumers- even mobilizing support to save shows on the verge of cancellation- fans are now beginning to be valued as cocreators of a show's narrative universe" (193). Sharma sees the relationship as one that encourages fan activity and acknowledges fans' power (193). Ryan Milner also notes the collaborative relationship between gamers and studios. Gamers often participate in a similar co-creation with their contributions of mods, or game extensions. Studios sometimes promote these fan mods, incorporate them into the game itself, or even hire talented modders to join the studio (Milner 495-96)

Fans demonstrate a devotion to the text, and will often collaborate with producers to act on behalf of the product. For example, sometimes, fans attempt to assist producers to act as custodians of a text, often for no pay. Milner in his work on fan labor in the Fallout gaming community and the New-Organizational paradigm, talks about how fans "[labor] for an ideal," that is more loyal to the text than the company or authors specifically (504-05). Fans work to benefit the text, in this case, holding discussions on ways to improve the game, offering suggestions and labor to producers, and crafting mods to be added to the game file for little or no profit to better the text. Milner notes that producers may be seen as exploiting fan labor; however, for fans the benefits outweigh the cons. He writes, "because of this desire to influence the official text, most fans... resigned themselves to labor within [producer] parameters" (501-02). Milner notes that fans are less concerned that their free labor is being exploited than that their work will go unacknowledged by 
producers,; fans see "themselves as just as invested in the product as... paid staff" (505).This dedication to the text, where fans are simply offering their own labor and efforts in an attempt to benefit the product, demonstrates that some collaborative fans acknowledge producers as the authority figures- the collaboration, if it happens, will be happening on the producer's terms.

Indeed, Williams suggests that fans are being lulled into a false sense of collaboration by the apparent accessibility of the internet, but that they ultimately lack substantive power. Williams outlines the producer/fan relationship as antagonistic, as "producers/writers often simultaneously encourage and deny the impact of fan's opinions and campaigns... [displaying an] authorial duality, both encouraging loyalty to the show whilst paradoxically cautioning against fan expectation that their desires be sated" (282). Williams believes that fans are laboring under the "illusion of reciprocity" and that fans in reality have "little impact" on the shows with which they're interacting (282).

The lack of reciprocity can encourage antagonism from fans who may challenge producer authority in various ways. Engaging with fan communities may be seen by producers as increasingly as a "necessary publicity evil... crucial to the success" of a product (Murray 8). While producers have successfully utilized fan networks for cheap and quick marketing and publicity (Murray 8), attempts to tap into fan communities to ensure a product's success can backfire on producers. For instance, George Lucas and Lucasfilm became too commercially focused in their promotion of the new Star Wars films, creating a website that requires paid subscription to access all of the material. They have further admitted that their 
priority is commercial success rather pursuing a connection with fans. In Lucas' perspective, "fans are a commodity to be commercially exploited, not a resource to be respectfully courted" (Shefrin 275). Due to his clear and explicit focus on commercial gain, rather than laboring for the text's sake, as fans expect, Elana Shefrin notes the "large decline in Lucas' symbolic capital" following fan disappointment with the first Star Wars prequel (270). Some fans even went so far as to circulate a petition, calling for Lucas to step back from involvement in Episode III and cede all his creative rights to the series to Peter Jackson, a producer who is well-known for successfully managing collaborative producer-fan relations (271). In his article, "Fan-tagonism," Derek Johnson further discusses how antagonistic fans challenge producer authority through "fan activism." Using the Buffy fandom as an example, Johnson explores the fan reaction to Marti Noxon taking over during season six, when fans pushed against Noxon's authority as a producer and custodian of the Buffy story (292). In this case the fans felt the material was being betrayed, and "worked to negate her authority" by constructing an extra-textual fan narrative that positioned Noxon as the villain of the show (293). Fans viewed her promotion as an "illegitimate takeover," that betrayed the vision of creator Whedon, privileging an idealized author over Noxon's producer efforts (293). Johnson argues that fans work to establish their own relational authority to a show's text, in order to safeguard what they perceive to be the essence of a show.

While fans may use their communications with producers to challenge producer authority, producers may use the text to discipline the fans. Producers can “construct 'acceptable' fan activity... by building critiques of unruly fans directly into 
the text" (Johnson 295). For instance, several characters in Buffy become stand-ins for fans and fan activity. Within Buffy these fan stand-ins bring fan readings to life quite literally in one episode. The character, named Andrew, works to create a record for others about Buffy and her team's efforts to prevent an apocalypse. This record however, is highly sensationalized, presenting a world that both "excuses his crimes while also embellishing his prior villainous prowess" (Johnson 297). He is ultimately stopped by Buffy herself who insists that he needs to stop telling stories and live in the real world, canonically disciplining fans away from their reimaginings. These fan surrogates are disciplined from "storytelling practice" into "compliant consumption," giving up their own alternative readings and acknowledging the authority of the sanctioned storytellers (Johnson 297). Thinly disguised as plot development, this episode can be viewed as the producer response to fans. The fan stand-in characters, serve as a cautionary tale to fans who get "too wrapped up" in their own transformative works. Fans can also be disciplined narratively through legal measures, such as the cease-and-desist letters sent to Harry Potter fan sites by Warner Bros (15). Fans were instructed to remove official names and references from their websites, as Warner Bros now owned the rights. As a result of immediate fan backlash, Warner Bros compromised by unveiling the "Webmaster Community," bringing these fan sites under a producer-sanctioned umbrella (Murray 16). While ultimately fans are "[dominated]" and "[disciplined]" by producer authority, examples of fan-tagonism and schisms illuminate a potential for fan resistance within antagonistic fan-producer relationship (Johnson 299). 
The different kinds of relationships fans share with producers can affect fans' status as fans. When fans are directly targeted and cultivated by producers, fans' participation is commodified and their activities move from the margins to the mainstream. Rather than fans acting as textual poachers, picking what they want to highlight in a text and 'playing' in that universe, fans become collaborators with an illusion of ownership that is manipulated by producers (Hills 37). As noted by Jenkins et al in Spreadable Media, "Transmedia extensions court affirmational fans" (Jenkins, Ford and Green 151). As opposed to transformational fans who twist and reimagine the source material, affirmational fans often "re-state the source material," and acknowledge the producers/creators/authors as having the final word on a show (150-51). Jenkins et al quote a fan critic, noting affirmational fans are the producer-"sanctioned fans," working within the boundaries set by the producers (Jenkins, Ford and Green 150; obsession_inc.). Affirmational fans investigate and focus on the puzzles and conflicts in the world of the text, more akin to a mystery to be solved than a site where fans can play with the story and rework it as they see fit. Affirmational fans will not perform a radical reimaging of the source material; they are more likely to craft stories that complement the canon.

In addition, fans who cooperate with producer authority are not able to enjoy the distance required to critically analyze and resist producer narratives to construct fan texts. By participating as producers and seeing those "values of authenticity... mirrored" in the production, the fans become locked into this vision, effectively hampering any creative transformations that they might have applied (Hills 37-38). As Hills notes, 
through seeing its own agenda on screen, fandom loses any possibility of creative textual mutation and thus becomes locked into its own rigidly maintained sets of values, authenticities, textual hierarchies, and continuities. (38)

Hills uses Will Brooker's examination of Batman as an example, noting that if fans had been allowed to stop the "bad" Batman films, then Batman as a character and story would suffer, "unlikely to retain the resonance and cultural hold which it continues to possess within contemporary culture" (Hills 38). In other words, a sense of antagonism and distance from the production process may be necessary for fans to maintain their critical edge as well as their transformational status.

\section{Method}

The fan/producer relationship has multiple aspects to consider, as both fans and producers each bring their own agenda and set of expectations to this relationship. Fans are now faced with producers who are 'in-the-know' about fan activities, allowing producers to code their text with meanings that they know fans search for and to cultivate relationship with fans. The fan/producer relationship can be collaborative, producing affirmational fans, or antagonistic, encouraging transformational types of fan activity

In 1.1 and 2.1 I provide a textual analysis of the shows of Supernatural and Sherlock, respectively, to highlight the queerbaiting tactics of each. I argue that producers deliberately code texts with implicitly queer meanings in an effort to appeal to fans and secure a broader audience. In these sections, I examine Supernatural's reliance on subtext to suggest and develop a relationship between the characters of Dean and Castiel. I examine how Sherlock more openly mocks fan 
assumptions of a same-sex relationship, and uses bromance tropes to insist on Watson's heterosexuality.

In response to such ambiguous texts, fans attempt to conduct conversations or search for answers to their questions by seizing moments where producers speak to fans at convention panels, Twitter Q\&A opportunities and live-tweet discussions. In 1.2 I explore moments of Supernatural producer-fan interaction over the course of the show until December 2013, as this covers the trajectory of Castiel's introduction through to the close of season nine, allowing me to examine interactions in the context of a finished season, providing a measure of storyline closure for fans. I argue that Supernatural producers actually encourage affirmational fans, and have developed a collaborative relationship, that works to regulate certain kinds of fan activity as acceptable. In 2.2, I will examine the Sherlock producer-fan interaction over the course of the show until December 2014 to include notable producer responses to fan shipping questions. This allows me to incorporate the most recent completed season, as well as the period of producer-fan interaction in the wait. The unique airing schedule of Sherlock leaves two years between the airing of new seasons, and fans are habituated to using this extended break to puzzle out questions posed by producers, as well as attempting to pose their own questions to them. In this section, I argue that despite attempting to cultivate affirmational fans, Sherlock producers have created an atmosphere for transformational fans to flourish. This is due to the antagonistic relationship between producers and fans and fans' distrust of producer authority. 
In both 1.2 and 2.2, I focus on moments where fans attempt to utilize communications with producers to start a conversation regarding the fandom's interpretation of the canon, specifically in terms of shipping. Following Simone Murray who examines producer/fan interaction in the Harry Potter and Lord of the Rings fandoms, I construct a narrative from producer/fan interaction that is emblematic of the conversation between fans and producers within Supernatural and Sherlock. Like Murray, who follows the producer/fan interaction surrounding promotional campaigns. I trace the producer response to fan inquiries about shipping and slash. I examine the traditional communication venues used by producers such as convention panels, LiveJournal.com, Tumblr.com, as well as DVD commentary and media interviews, which are widely recognized as the locus of fan discussions and activity. I'm focusing on shipping because despite the increasing commercial desirability of the fan to consumers (Hills 38), slash fans remain a transgressive element of fandom that is being brought increasingly into the mainstream. As both Supernatural and Sherlock are still active shows, these are very much ongoing conversations.

Outside of their conversations with producers, fanfiction is another venue for fans to express their textual re-imaginings or resistance to producer authority. In 1.3 I examine Supernatural fanfiction that is considered "classic" within the fandom. Through an examination of these stories, I demonstrate how Supernatural fans largely work within the boundaries of the show, and overall exhibit more homonormative tendencies in their works. This is a notable difference from the traditional academic construction of slash fanfiction as subversive and resistant. In 
2.3, I analyze "classic" fanfiction of the Sherlock fandom. In this section, I explore the ways that Sherlock fans subvert normative expressions of desire and sexuality, explore neuro-atypical characters and tackle explicit questions of sexual identity. These works are decidedly queered, resistant spaces that serve as a strong demonstration of the potential of transformative works. By examining these stories, I attempt to show how the different fandoms imagine fanfiction in different ways. I argue that the Supernatural fanfiction embodies a more affirmational fan identity while the Sherlock fanfiction reflects the fandom's transformational status. I trouble the traditional academic construction of slash fan spaces as subversive and queer, detailing how homonormative themes have become dominant in 1.3, while works examined in 2.3 retain their queer subversions of the text and larger societal norms. My varied sites of analysis will provide a more holistic understanding of the communicative nature of fandom today as well as an increased understanding of the relationship slash fans have to show and production teams that queerbait. By that, I mean that this work will attempt to take into account the breadth of the material that fans engage with, from the text of the show itself, to creative fan works, to the discussions and advocacy work that they perform through social media and venues with the cast and production staff.

However, my research has several limitations. For sake of brevity, this work is only able to explore slash fanfiction, yet again leaving femslash out of a critical analysis. For specificity, this research will focus on two fandoms in particular, that of Supernatural and Sherlock. My analysis is by no means meant to speak to the entirety of fan experiences. While I would love to explore in detail the effect fan 
activity and, in some cases, fandom pressure, have directly on the show, without speaking to the writers or producers, that link is unfortunately difficult to determine. I am also unable to demonstrate a direct causal relationship between producer-fan interaction and the homonormativity of fan works. There are many other factors to consider that would influence the types of fanfiction produced, such as the type and quality of the narrative itself, among other things. Instead, I hope to examine the different kinds of fan cultures produced in the new media environment in which producers court fans via queerbaiting and other practices 


\section{"A MORE PROFOUND BOND:" A CASE STUDY OF SUPERNATURAL AND ITS FANDOM}

\subsection{Textual Analysis of Supernatural}

The television show Supernatural premiered on September 13, 2005 on The WB network. Following the merger with UPN, the show now airs on The CW. Created by Eric Kripke, the show is currently in its tenth season with 209 episodes. The show stars Jensen Ackles as Dean Winchester and Jared Padalecki as Sam Winchester, the brothers who are the main protagonists of the show. Supernatural follows the Winchester brothers as they continue the "family business" of hunting supernatural creatures to keep people safe, traveling across America to investigate any cases of supernatural activity.

This case study of Supernatural and its fans has several goals. First, I will look at the text of the show to demonstrate how producers court fans through the practice of queerbaiting. Supernatural has been knowingly been encoded with a homoerotic subtext in ways that appeal to fan sensibilities. Second, I will focus on producer-fan interactions to show how the producers have augmented this subtext with teasing or ambiguous statements when fans ask them about the relationship, never denying but never explicitly naming the relationship as homoerotic. I will also show how producers have positioned fans as collaborators, and how that relationship is strained as fans increasingly seek answers regarding the text's 
queerbaiting and producers attempt to remind fans of their expectations of affirmational, sanctioned fans. I then analyze fan works of Supernatural, considered "classics" within the fandom to explore if fans are resisting producerly authority. I argue that Supernatural fanfiction has incorporated homonormative themes and is not the resistant, transgressive space fanfiction has been imagined to be.

Examining the text of the show is extremely important, as it is the common canon that is shared by the fan. In order to participate in the fandom, shippers must have knowledge of the facts of Supernatural, or the canon. As stated by Rhiannon Bury,

the issue of canon is the one feature unique to fanfiction. In the popular culture context, the term refers to the characterization and character development across the history of the series. The term clearly mobilizes a discourse of authority: like the literary canon, the primary text is not to be trifled with. (100)

Bury's words hold true regarding the place of the canon in fan art and fanfiction. In their fan texts, Supernatural fans demonstrate a reading of the text which understands an intimate relationship between the characters Dean and Castiel, an inference based on characterizations and events in the canon. Supernatural is a show dominated by male characters, and as Shoshanna Green et. al find, "fans see everything in the context of the show itself. If an actor, or a pair of them, are busy projecting rampant sexuality, the fan mindset is to look within the program for the object... Strictly within the show framework, there's nobody but the two men... so the concept of slash arises" (17). In other words, in a show that has largely killed off the majority of its female characters, fans are left projecting romance and desire between the only options available, the male characters. I'll be focusing on moments 
within the show that many fans point to as notable evidence of an intimacy between Dean and Castiel. As Castiel was introduced in season 4, I focused on seasons 4-9, for a total of 135 episodes examined. Within section 1.1, I will demonstrate how producers have encoded a queer subtext, deliberately incorporating common slash fan interpretive strategies in their depiction of the relationship between Dean and Castiel. I have viewed all episodes of Supernatural through season nine, and have focused on the relationship between Dean and Castiel, particularly highlighting moments that many Destiel fans have focused on in their own viewings of the show.

From the very beginning, Castiel's character interactions with Dean were presented in ways that adhere to the conventions of slash. In the fourth season, Castiel was introduced as the angel who had saved Dean from Hell and brought him back to life. During this season he interacted primarily with Dean and the tone of their conversations, commonly intense and with little personal space between the pair, coupled with Castiel's role as Dean's savior, lent itself to an easy reading of a beginning attraction. Castiel's early scenes showcased an intensity between the two characters, which contributed to the sexual tension that slash fans read between the two characters. Most of Castiel's interactions are with Dean. He often visited Dean when he was alone in his hotel room, or in the middle of the night, while Sam was sleeping, creating a sense of intimacy to their interactions.

A scene in the second episode could easily be taken from any slash work, so closely does it mirror the many tropes of slash "first time" stories. Castiel pays Dean a visit in the middle of the night, and Dean criticizes Castiel's lack of involvement, 
causing Castiel to bristle. Throughout the conversation, the two move closer to each other, and Castiel deliberately invades Dean's space, slowly stating, "You should show me some respect. I dragged you out of hell and I can throw you back in" ("Are You There God? It's Me, Dean Winchester"). Dean, up until this point in the show, has been a "man's man," performing an aggressive, traditional masculinity replete with classic rock, leather jackets and muscle cars. However, in this scene he is cowed into submission by a much smaller man who looks like a corporate drone in his rumpled suit and trench coat. The writers here seem to be engaging the "genderswapping" attributes or, a "combination of masculine and feminine elements... crucial to representation of gender in slash" (Woledge 55). Indeed, fans typically cite these moments of intensity as examples of a brewing passion between the two.

Bacon-Smith talks about how fans she met with "perceive and agree on at least three interpretations of intrusion into personal space: interpersonal intimacy, aggression, and dependency" (233). The scenes here can be read in the same ways, working to establish a subtext of sexual tension, of passion behind the aggression and a deepening intimacy. Elizabeth Woledge notes, "for many authors, it is intimacy rather than sexuality that is the centrally important element" (57). I view aggression and dependency as signs of that intimacy, as aggression and dependency demonstrate heightened emotions between the two, indicating to viewers that these characters have something compelling between them, something that draws, which many fans read as sexual tension. 
That subtext of sexual tension gradually increases during the show. Near the end of season five, Dean is ready to accept his role in bringing on the Apocalypse, prompting Sam and Castiel to place him under a "house arrest" of sorts. Sam and Castiel confront him on his sudden decision to accept passively his "fate." Throughout this conversation Dean keeps his focus on Castiel, affected more by Castiel's reaction to his surrender than Sam's. He manages to quip, "Cas, not for nothing, but the last time someone looked at me like that... I got laid" before Castiel walks away ("Point of No Return"). This relates back to the eroticization of aggression, a sign of intimacy between the characters. Dean appears to perform the role of the slash fan here, reading Castiel's anger with him as a sign of sexual tension. Later, the pair fight as Castiel tries to remind Dean of why they're fighting and how much he has given up to follow Dean into battle. This entire sequence reads as a "battle for dominance," a typical feature in slash stories as the characters fight over which plan will be utilized- significantly, the plan that the two crafted together is the one chosen (Jenkins 211).

In addition to the sexual tension between the characters, Supernatural has also constructed what can be read as romance or emotional intimacy between Dean and Castiel. In Supernatural, angels are portrayed as very emotionless, highly obedient, characterized more as "warriors of God," rather than accessible guardian angels. This characterization makes the conversation between Castiel and Dean remarkable to fans, as Castiel makes a dramatic break from the "party line" demonstrated by other angels. As the two are sitting, looking at a park of children saved by Dean's insubordinate actions to take a tactical loss in the war but keep the 
town alive, Dean is adamant about his decision to lose the seal but save the town, and is surprised when Castiel agrees with him. The angel quietly confesses "I am not a hammer, as you say. I have questions, I- I have doubts... I don't know whether you passed or failed here..." After this small speech, there is a moment of extended eye contact between the two (which touches on the pair's staring trope in fanfiction, which will be discussed later within this paper), while music softly plays in the background ("It's the Great Pumpkin, Sam Winchester"). In this scene Castiel shares something monumental for a "soldier of God," who is programmed to obey. His character, rather than indulging in the (literally) 'holier than thou' superior bearing of his angelic peers, instead chooses to share his internal conflict and explain himself to a human. He refutes Dean's accusation that he was simply a hammer wreaking destruction. This conversation indicates that Castiel, despite his relatively short association with Dean, cares about Dean's opinion of him. Rather than dismissing Dean as an inferior being, Castiel views him as a peer. Acknowledgement of equality within the partnership is inherent of much of slash fiction, as Mirna Cicioni notes, and Supernatural provides this acknowledgement in canon (169). Establishing equality between the characters speaks directly to slash sensibilities, as "slash fiction is basically a fantasy of authentic love which can exist only between equals; specifically people who are strong and share adventures as well as emotions (169). Supernatural is tapping directly into slash strategies as it develops the relationship between Dean and Castiel. Despite Dean's canon history of womanizing, they've left open possibilities for queer readings by displaying Dean's heterosexuality as inconsistent, particularly in "Everybody Hates Hitler," where 
Dean is presented with another man flirting with him and performs a romantic comedy-esque fluster, never quite dismissing the advances.

The confession of feelings is an integral part of the slash formula (Jenkins 214). Throughout the show, both Castiel and Dean share dialogue that borders on a confession. Soon after Castiel appears, the potential for an emotional connection is emphasized when he sends the brothers on a hunt. Dean disagrees with Castiel's insistence on adhering to the rules of life and death, wanting to save everyone he can while Castiel insists, "To everything there is a season." Dean, frustrated, points out, "You made an exception for me," when Castiel brought Dean back to life and saved him from Hell. This prompts Castiel to simply look at Dean for a moment, stating, "You're different," before disappearing to presumably attend to other Heavenly business ("Death Takes a Holiday"). In this scene, Dean is established as a highly important, potentially perspective-redefining person in Castiel's life. This is further emphasized throughout the show, as Castiel's originally rigid moral sense of right and wrong and obedience to Heaven's agenda shifts to support the Winchesters, particularly Dean. Castiel demonstrates a willingness to compromise and sacrifice anything to support his Righteous Man, the role that Dean fills during the show. Castiel's drastic change and fall is well-noted, as an angel who previously served with Castiel is outraged at Dean's request for her assistance, making her disgust clear, "The very touch of you corrupts. When Castiel first laid a hand on you in Hell, he was lost!" ("Reading Is Fundamental"). Dean becomes Castiel's new driving cause. Fans read this as an acknowledgement of the importance Dean holds for Castiel, an intimate moment between the two. This reading is supported by the 
actor who plays Castiel, Misha Collins, who notes in a 2008 interview, "It seems to me that the main focus is my relationship with Dean," (D. Williams). Indeed, Castiel proceeds to choose to fall from Heaven to help Dean avert the apocalypse, willingly cutting ties and rebelling all for the sake of Dean. The ramifications of the averted apocalypse and the broken factions in Heaven are a driving force in season six. These narrative events demonstrate that writers are intentionally depicting the relationship between the two characters as important and even world-shaping.

Supernatural strongly emphasizes loyalty. What has developed within the show is a hierarchy of loyalty. While the brothers demand trust and transparency between one another, frequently they're shown betraying one another as they attempt to do what they think is best for the other. This dynamic is also expanded to Castiel and Dean. Whether this is at the expense of humanity and losing a battle during the Apocalypse or giving up a substantial campaign for power in Heaven, both characters demonstrate an understanding that alliances will be broken for one another, no questions asked.

The writers code the show for viewers to pay particular attention to the dynamics between Castiel and Dean. When Castiel is not transparent with Dean, the text implies a deeper betrayal between the two, indicating how close Dean is to Castiel. At the end of season six, Castiel amasses an army so his faction may rule Heaven and keep the opposing side from trying to achieve the apocalypse. He collaborates with the new King of Hell, Crowley. Within this collaboration, Castiel is trying frantically to keep Sam and Dean safe from Crowley's demons. Meanwhile, 
Sam and Dean work with another hunter, Bobby, to find Crowley and stop him from expanding his power. Bobby and Sam are convinced, rightly, that Castiel is working with Crowley, assuming that Castiel is working on an evil plan with the King of Hell and conducted their own investigations into Castiel's allegiance accordingly. They view Dean, because of his close relationship to Castiel, with a measure of distrust, as it is simply assumed by his surrogate father and brother that he would share what he knows with Castiel. When they voice this concern, Dean valiantly tries to defend Castiel, while Castiel invisibly observes. Castiel later notes "And the worst part was Dean, trying so hard to be loyal, with every instinct telling him otherwise" ("The Man Who Would Be King"). Despite every indication otherwise, Dean fights with his brother and surrogate father figure to defend Castiel. When faced with undeniable proof of Castiel's betrayal, Dean is angry not at Castiel's choices, but that Castiel didn't reach out to him for help. Within the show's narrative, a hierarchy of loyalty is established, and the "profound bond," between Dean and Castiel, as the latter described it, seems to take priority repeatedly ("The Third Man"). Throughout this episode, both Castiel and Dean are shown to have a deeper connection to one another than Castiel has to Bobby or Sam. With a simple look from Castiel, Dean determines the truth of his betrayal. At this moment of revelation soft music begins playing in the background, a mournful horn and piano trill, providing a dramatic soundtrack and signaling to the viewer that this is an important emotional development.

Castiel and Dean's relationship becomes so important that it forms the bulk of Dean's character conflict during the eighth season. In season eight, the writers 
imply something deeper than friendship between Castiel and Dean. The season uses flashbacks to tell the story of Dean's time trapped in Purgatory with Castiel. After he was left by Castiel, Dean learns of a 'back door' to Purgatory that he can utilize as a human to escape back to Earth. Instead of finding this back door immediately, Dean insists on scouring Purgatory for Castiel, who had disappeared and left Dean. When Dean finally catches up to Castiel, he immediately pulls him into a hug, a notable moment for a man who detests "chick flick moments," who is notorious for avoiding conversations about feelings and who, outside of expressing sexual interest, doesn't indulge in physical affections ("Pilot"). The dialogue and physical display of affection shows the emotional importance the characters hold for one another. Dean is convinced that Castiel was taken out by a monster and they were simply separated. Castiel admits otherwise, that he left to keep Dean safe from the monsters who would be drawn to the angel. Dean is upset and insists that Castiel accompany them to the exit to bring him home, blatantly stating, "We'll figure it out. Cas, buddy, I need you... Let me bottom-line it for you. I'm not leaving here without you. Understand?" ("What's up, Tiger Mommy?"). Dean's lines are a transparent declaration of not just want, but need for Castiel, admitting that he prayed to Castiel every night, and tying his personal safety to Castiel's. Dean, who usually does everything in his power to return to Sam, delays that goal. His willingness to put that on hold or even leave Sam behind completely for the sake of Castiel is a monumental moment in the relationship of these two characters, implying a greater relationship, such as a romantic partner, is at stake here. In addition, at the beginning of the conversation, music begins to play softly, a distinct chord being 
held on the higher strings. There is a moment of silence as Castiel confesses he left Dean intentionally. As Dean insists on Castiel accompanying him home, a cello enters, an interesting choice considering the association the cello has with romance and eroticism in music (Gómez). Supernatural is clearly coding Dean and Castiel's relationship as important; their partnership is essential to the plot, and their relationship with each other is integral to their individual character development. To communicate this, Supernatural utilizes musical cues to indicate viewers should pay attention to these emotional moments between the pair, as well as an enormous amount of subtext and coded language, such as the notion they share a "profound bond."

Castiel is later shown to be equally as dedicated to Dean. Taken from Purgatory by another angel named Naomi, he is brainwashed to find the angel tablet, a long lost 'Word of God' at all costs, including killing Dean if Dean interferes. After finally locating the tablet with enemies closing in, Castiel realizes that he needs Dean to access the tablet, even though once it's in Dean's possession, he won't relinquish it in order for Castiel to take it to Heaven, because Dean knows it is a bad idea to trust the angel establishment. Castiel's vessel, his physical body, begins to act on the orders programmed by Naomi, and begins to attack Dean. Inside his mind, Castiel attempts to resist and regain control of his vessel, asserting, "I won't hurt Dean." Meanwhile Dean steadfastly believes that Castiel is not fully in control of his body, talking to him through the assault. As Castiel continues to beat Dean silently, breaking his arm and leaving his face a bloodied mess, Dean pleads, "Cas. Cas. I know you're in there. I know you can hear me. Cas... It's me. We're family. We need 
you. I need you" ("Goodbye, Stranger"). The entire scene feels as though the writers have engaged in slash fanfiction of their own. "Hurt-comfort" is a well-known genre of slash, where "the injury or near-death experience of one of the partners (or death of another significant character)... force a recognition of the fragility of their relationship and what would be lost should their friend be killed" (Jenkins 209). Dean is faced with the real possibility that his partner may be gone, lost to the political machinations of Heaven. This moment of raw emotion seems to be enough for Castiel to regain control of his actions, Castiel stops and reaches out, grasping the side of Dean's face to heal the damage he'd caused. The original script before being changed culminated in an explicit declaration of love, with Dean declaring, "I love you," instead of "I need you" (Thompson). This type of confession follows the slash formula, in which characters acknowledge their feelings before it's "too late," and one dies. While the show never makes an explicit acknowledgment of sexual love between the characters, the scene still indicates an intense, affective connection between the two.

These moments throughout the show are all supplemented by regular references by other characters who comment on Dean and Castiel's unique relationship, often explicitly naming them as partners. These comments are usually directed at Dean, and indicate that there is widespread acknowledgement of the relationship between Dean and Castiel. For example the angel Balthazar tells Dean, "you have me confused with the other angel. You know, the one in the dirty trenchcoat who's in love with you" ("My Heart Will Go On"). Even demons, like Meg are well aware of the partnership between Castiel and Dean, snapping at Dean when 
he asks her about Castiel's erratic behavior, "Ask him, he was your boyfriend first" ("Survival of the Fittest"). Commentary by other characters shows how the primacy of Dean and Castiel in each other's lives permeates the world of the show. These lines, if taken literally, imply a physical element to a relationship that has thus far remained solely emotional onscreen. Neither participant actually corrects the assumption that they are a couple, a fact that allows fans to interpret this silence as room for potential- they may not be confirming it, but they're also not denying it either.

While the scenes described above are often noted by fans for developing sexual tension and constructing an emotional connection between Dean and Castiel, fan desires are undercut by other moments in the canon. It is important that the two are never actually explicitly presented as being in a relationship. In fact, the writers have taken pains to assert Dean's heterosexuality. Dean is portrayed getting intimate with several women over the course of the show, such as past flames, Cassie and Lisa, as well as a fallen angel named Anna ("Route 666"; "Heaven and Hell"; "Swan Song"). In addition to these dalliances, the show occasionally depicts him flirting with female bartenders and waitresses on the road, as well as frequently consuming his pornography of choice, "Busty Asian Beauties."

Thus, the show producers deliberately code multiple meanings into the text, making use of lingering glances and romantic music and providing situations during the show that can easily be read by fans as queer while simultaneously refusing to acknowledge an explicitly queer relationship in the text. This is the "sensible business strategy" of queerbaiting (Sender 303). Selling notes that gay men are 
viewed as "desirable models of consumption," especially ones who are suitably masculine enough to "allow for multiple points of desire," which Dean and Castiel, with their conventional good looks and performance of a tough, capable masculinity absolutely fit (Sender 304, 09). With gay window dressing, or queerbaiting, the relationship remains subtextual and producers don't alienate conservative heterosexual viewers who can still view Dean as desirable and accessible, as well as leave the door (wide) open for fans' increasingly popular practice of slash shipping.

While some can view a queer subtext as subversive, a step towards progress in terms of media representation of LGBTQ sexualities, I instead believe that the current practices of the show function as queerbaiting, ultimately doing more harm than good to the audiences that watch it. For example, the fact that Dean or Castiel do not correct those who assume they are in a relationship, allows shipping fans to remain hopeful. At worst, however, such moments offer a substantially grimmer possibility. It is notable that moments in which other characters comment on their relationship often occurs as a brief glimpse of levity in an otherwise grave or urgent situation. The fact that these exchanges are moments of relief in tense scenes ultimately can be read as positioning same-sex relationships and queer identities as the punchline. The narrative attention paid to the development of the relationship between Dean and Castiel, would make this expression of homophobia that much more insidious. Teasing about a relationship and building a hefty subtext surrounding without any explicit mention or confirmation reinforces the silence around queer identities, stigmatizing them and reinforcing hegemonic sexual norms. 


\subsection{Supernatural's Fan-Producer Relationship}

In this section, I examine the producer-fan interactions to determine the types of fans that are being cultivated by producers: affirmational or transformational fans. I also work to determine whether a collaborative or antagonistic relationship between producers and fans has developed. I argue that Supernatural producers, while paying lip service to traditional fan activities by encoding a queer subtext and making various allusions to Destiel in their communications to fans, are actually cultivating "acceptable" fan responses. They only engage with fans who remain in the boundaries that have been outlined for fans. These include such as only discussing slash in designated spaces or with designated representatives, and by respecting producer authority by taking their fan transformations only to a certain point. When fans remain in these boundaries, they enjoy a close, collaborative relationship with producers.

Supernatural fans enjoy a particularly open relationship with producers, as the show has long since embraced transmedia engagement. Writers, producers, and actors on the show have fully embraced Twitter. Staff can often be found "hosting" a live-tweeting session during the airing of new episodes, offering behind-the-scenes snippets and reactions to the finished product, as well as answering fan questions about plot, or simply conversing. Supernatural also enjoys a prolific convention schedule that since 2007 has been well-attended by show staff. Between the producers' invitations to fans to participate in staff-hosted conversations on Twitter, and their direct interaction with fans at conventions, Supernatural's production team has developed an air of accessibility. Fans feel comfortable responding to 
producers, or even attempting to start conversations. Fans also participate outside of the show, interacting with the cast and crew, following interviews, taping conventions, etc.

I've highlighted some notable moments of interactions between fans and producers. These are moments that are significant within the fandom because of producer statements referencing or discussing fans' slash activities. Producer messages here, despite the friction caused by some fan calls for explicit discussion of sexuality and identity, remain largely couched in the supportive, encouraging tone that fans have come to expect from Supernatural. I hope to trace the Supernatural producer-fan relationship by examining these infamous moments. In addition, I will examine how the producer message regarding Destiel and the communication style of the show staff has evolved over time in their communication with the fans to develop a more collaborative relationship that sanctions fan activities that are largely affirmational in nature.

This communication style of being particularly accessible has been a means of survival for the show. Supernatural has consistently been saved from cancellation by the efforts of fans, and seemingly in return, there is a history of making sure fans tastes are catered to. This is evident through decisions like the casting switch-up that killed off the character of Bela, who was unpopular with fans, but substantially expanded the character of Castiel, whom shipping fans adore.

The fan community knows that their activities, including their discussions and responses to the show, reach the show's staff, and look for signs of that 
recognition. Fans are aware that their responses influence the show, and through the use of hashtags like \#SPNFamily, are perhaps more inclined to view themselves as "collaborators" with the producers (Jenkins, Ford and Green 173). The accessibility that the producers and staff maintain with fans serves as an indication that fans are being treated as "collaborators." Jenkins et. al describe collaborator fans as

complicit with the dominant regimes of power, yet they often also use their incorporation into that system to redirect its energies or reroute its resources. At the same time, companies often have to tolerate behaviors that may have once been seen as resistant or transgressive if they want to court the participation of these networked communities. (173)

In other words, Jenkins et al note the potential for fans to work "from the inside" and transform the institution.

While Jenkins et al observe that producers have to tolerate fans' slash activities, what is actually happening is that certain slash fan activities become sanctioned. In Supernatural, fans can broach the topic with only designated individuals like Collins who will entertain the interactions, another indication that producers are "[engaging] audience activities through strategic support for a delimited realm of fan creativity" (Murray 11). It becomes acceptable to joke or make light of the queer subtext presented in Supernatural, almost an inside joke of acknowledgement between fans and staff; however, any actual advocating for or serious discussion of the Dean and Castiel pairing is met with coy statements or silence. Another pairing like the previously dominant Wincest, in contrast, is only 
ever used as a reference for "crazy" fan activities, an example of radical fan behavior that isn't encouraged at all.

In one of the first instances of producer and slash fan interaction, we see the limits of how producers' tolerance for "resistant or transgressive behaviors" at a May 2007 convention called "Asylum." The interaction demonstrates how producers know about Wincest, but present the pairing as unacceptable. This was the first convention attended by show staff, including Jensen Ackles, the actor who portrays Dean Winchester. At the time, Supernatural was just about to finish its second season, years before the introduction of the character Castiel. During a Q\&A session at the convention that was filmed and shared on YouTube, an audience member asked Ackles what he thought about fanfiction, eliciting scandalized gasps and laughter from the crowd. The fanfiction that she was referring to was "Wincest," slash fanfiction exploring a romantic relationship between the two brothers, Sam and Dean Winchester, something that has largely dropped in popularity after the introduction of Castiel. Ackles rubs his face, indicating his reluctance to answer as the crowd cheers, seemingly surprised that he's going to answer it. He jokingly refers to them as "crazy" and "sometimes very disturbing," with a dry tone, implying these are tame ways to express the depth of his distaste for these aspects of fan creativity. Ackles quickly jokes that "One of my favorites is Wincest... Jared and I had a good laugh about that one. It was only brought to our attention because [director] Kim Manners had posted it," before directing the crowd to move on to other subjects (Padalecki). His answer to the question was met with cheers and applause at the mention of Wincest and again as he finished. 
Ackles' response indicates several things, first, that the producers of Supernatural are aware of the fan community and their activities. Second, that while they are aware of it they've shared it with the rest of the show's staff, which Ackles indicates. They are at best reluctant to discuss it and ideally would not. Third, that while the producers may not endorse such fan interpretations, it's viewed as a quirky fan activity. This is a very early example of how the producers are beginning to position the fans as collaborators. Producers, via Ackles' story, are demonstrating their fandom savvy, and rather than immediately condemning slash fans, make light of the activity. Ackles, understandably not being completely onboard with sibling incest, still had the conversation with fans. He was willing to answer a question about shipping, a common fan activity, and share with fans that not only do the staff have an awareness of these fan activities, they've actually encountered some fan works. Here, Ackles' response and status as producer representative serve as a gentle correction to fans- they know about Wincest, but it's viewed as weird and disturbing. While not overt, it serves as a subtle indication for fans of a new boundary to consider, which the crowd, based on their slightly embarrassed laughter, may have received.

After Misha Collins' character Castiel joined the show in season four, fans flocked to a new pairing, Dean/Castiel, and the incredibly positive fan response to his introduction led to Castiel, originally planned for a six episode arc, to become a regular cast member (Spelling). With the release of the season five DVD set, the fans of the Dean/Castiel pairing thought they had another moment of acknowledgement from the show's actors: a blooper scene where the camera is in a close-up on Ackles' 
face, with Collins in the background, out of focus. Looking into the camera, Ackles mimes giving a blowjob, pointing back to Collins and then himself, with a wink and a nod. Many fans took the opportunity to preserve the moment through gifs, chronicling it with images they felt supported Destiel from the show. A "wink wink, nudge nudge," response, of course, is not confirmation of a relationship or interpreted as a promise to fulfill. However, fans viewed the blooper as another example of the staff speaking to the fan community, where the actors are even joining in for a laugh.

There have been repeated statements from actors and crew that are meant to imply that someday there might be a chance for Destiel to become canon within Supernatural, such as producer Jeremy Carver calling himself a "fan" of Dean and Castiel (Goldman) and the DVD commentary discussion between directors and writer/producers like Sgriccia and Edlund. Later, at a convention in October 2012, other staff implied a future validation of fan activity- a possible canonization of Destiel. Misha Collins, participating in a meet and greet with the fans, was asked about the producer hint for the upcoming season eight showing a "relationship that the fans like to speculate about being resolved." Collins agreed that the hint was easily applicable to Dean and Castiel, saying theirs was "really the only love relationship on the show it could apply to" (K.). When the fans expressed their surprise at Collins' agreement with fans' view of the slash relationship, Misha, who appeared visibly impatient at their surprise stated

"I think the love there is made pretty clear...You know, we know what it is, what's going on. We don't talk about it. The actors don't, Jensen and I don't. 
But we're all perfectly aware of how the relationship is, the writers are completely aware of how it's being written. It may be unspoken but that doesn't mean it's not there or not true."' (K.)

Collins' response indicates that the relationship fans are asking for is already wellestablished. His answers to the inevitable questions give fans hope and validate their own readings of the relationship.

Other staff keep returning to and teasing the possibility of a Dean and Castiel relationship. With the release of the season eight DVD set, Destiel fans found another moment of excitement and recognition. During the commentary of "Everybody Hates Hitler," director Phil Sgriccia and writer/producer Ben Edlund discuss a scene that garnered attention with the fans when the episode aired. The scene happens when Dean confronts a man he believes is following him. The character, Aaron, corrects him, telling Dean that he is there to flirt with him. During the commentary, Edlund discusses Ackles' acting in that moment, noting 'it reads in this weird way where it does feel like Dean's a little bit like-it's almost like a romantic comedy kind of fluster. Which is very interesting for the character Dean, because it just sort of suggests this weird... this potential" (katiuska2h). This moment highlights that producers and directors are aware of Dean's potential for a same-sex attraction and intentionally left it in the episode. Once again, they create a possibility for Destiel fans without committing an explicit representation of a queer relationship.

Supernatural producers are exceptionally savvy social media users, which is another way they demonstrate their recognition of the fandom. In the digital age, 
live-tweeting during television shows is a common practice, and any fan community member can easily find people associated with the show on Twitter and contact them with reactions, questions, or simple compliments. This turns show airings into "events" where people can participate and have a festive conversation with the show staff. However, when events in the show disrupt common fan imaginings, the conversation can get especially tense. As noted in "Fan-tagonism," fans "can challenge corporate producers by constructing interpretative consensuses that delegitimize institutional authority over the hyperdiegetic text" (Johnson 291). In other words, fans at times may challenge producerly authority over the text if they feel that these producers are going against the established canon.

This is particularly well demonstrated in season nine, the most recent completed season of Supernatural, when the collaborative relationship between producers and fans hit an obstacle over events depicted in the canon. Castiel is sent away by Dean, who denies him shelter to ensure Sam's survival. Such an uncharacteristic move between the established partnership outraged many fans. Because the regular show directors and writers were taking a Twitter hiatus, one of the staff shifted fan tweets to executive producer, Chad Kennedy. The angry tweets began to pile up from fans who were angry regarding the plot developments currently airing. Kennedy, who had little day-to-day interaction with the show, became more and more turned around. At one point he professed support for an LGBTQ lead character, but insisted that it wasn't their plan for Dean and Castiel (Redcoast). As fans replied, Kennedy urged them to keep watching, that with enough time, the topic might be broached. Kennedy's conservative answers launched 
another wave of tweets as fans were suddenly responding to Kennedy's statements on the show's direction. As the onslaught continued, his tone shifted to a more and more conciliatory one, professing his support for "better representation of the gamut of sexual orientation on TV" (Redcoast). Eventually, the pressure from this episode caused him to delete his Twitter account.

Other Supernatural staff however, worked to reconcile the offended fans back into the producer's vision. The writers and producers, after the dust was settled, engaged with the fans, reminding them that the crew was always more interested in audience interpretation rather than imposing author intent (Redcoast). Actor Osric Chau and writer Adam Glass took to Twitter later to calm fans, Chau reminding the fan community that this is a show "where anything is possible," and Glass stating that it's the job of showrunners and writers to answer story questions, implying that it wasn't Kennedy's place to answer questions about the story for the upcoming season. The staff seemed to be focusing on the initial tweets regarding the plot development, largely sidestepping any fan criticism of Kennedy's definitive answer regarding character sexuality. The staff were yet again telling fans to simply wait and it could be "possible," at the same time as cultivating the "engaged viewer" (Jenkins, Ford and Green 134; Redcoast). The statements of Chau and Glass renewed optimism for many Dean/Castiel fans. In this way, Chau and Glass worked to placate and silence fan efforts that could really be considered transformational: calls for an explicit labelling of the Dean and Castiel relationship as queer. Fans were guided back into the affirmational space of undefined optimism offered by the vague comments of show writers and staff. 
The producers and staff have indicated their awareness of slash but have trained the fandom to view it as a topic that should remain subtextual and not be directly or explicitly expressed to producers. Perhaps as a result of this, fans seek to placate and demonstrate their own acceptability by collectively shunning anyone who pushes the "wrong" questions or readings and offends producers. For example, the actor who plays Dean, who initially joked about Wincest in 2007, has since become notorious in the fandom for being uncomfortable at the mention of any shipping or subtext questions with his character ${ }^{1}$. At a panel in May of 2013, a girl began the question and answer portion with, "I love your character becoming more comfortable with himself over the season. I'm bisexual and-"at which point Ackles expressed dismay that the first question was about queer identities and stated, "Don't ruin it for everybody, now." While the fan tried to explain that she wasn't attempting to be disrespectful, Ackles continued, “I'm gonna pretend I don't know what the question was. So I'm gonna take my cue and move on" (Redcoast). Collectively, the crowd, familiar with Ackles' stance on such questions, actually began to boo the girl. Ackles' and Padalecki's bodyguard stopped her question, and she left the microphone, visibly upset. Another fan who came forward later to ask if the actors would be willing to participate in the It Gets Better project shared a similar experience. She was rejected by Ackles before she could ask. While some fans criticized his handling of the situation, others notably fans sympathized with

\footnotetext{
${ }^{1}$ Ackles has been noted as the reason behind a script change during an episode in season eight, a very well-known incident within the fandom. The script called for a "showdown" between a mind-controlled Castiel and Dean. In it, Castiel viciously attacks Dean, who doesn't fight back and begs for Castiel to "fight" the control. Originally the script called for Dean to say "Cas. Cas. I know you're in there. I know you can hear me. Cas... It's me. I love you." The declaration was instead struck in favor of, "We're family. We need you. I need you" ("Goodbye Stranger"). However, Ackles suggested to the writers that the line as written wouldn't be in character for Dean and it was changed (Thompson).
} 
Ackles' discomfort (Romano "How One Question Triggered a "Supernatural"

Fandom Meltdown"). Ackles' knee-jerk response to shut down any discussion or even mention of non-normative sexuality makes clear that if fans are viewed as too transgressive they will be excluded from producers' conversations with fans.

Producers of Supernatural work to discipline fans in other ways. Within the text itself, Supernatural has long included fan acknowledgements, although the interpretation of these fan representations is often split in the fandom. One of the earliest fan acknowledgements comes from the introduction of Becky Rosen, who we first meet as she is writing slash fanfiction, specifically Wincest. She's narrating her dialogue as she goes, which is heavy-handed and stilted. Becky Rosen embodies many of the negative fan stereotypes, she's obsessed and sex-focused. When she is told that the Supernatural books are real and the brothers do exist and need her help, she protests, "Yes, I'm a fan, but I really don't appreciate being mocked. I know that Supernatural's just a book, okay? I know the difference between fantasy and reality" ("Sympathy for the Devil"). It only takes one more insistence for her to return to nearly hysterical levels of excitement, declaring that she knew it all along. Becky was introduced as a transformational fan, one who read a queer relationship to the brothers and was mocked in the text accordingly. She was only redeemed in season five when she becomes involved in a realistic relationship with another character rather than the "characters" she was obsessed with. Becky provides valuable assistance, her thorough knowledge of the books helping the boys track down the important Colt gun. Becky is thus redeemed when she occupies the role of 
the affirmational fan, working solely within the boundaries of the world without reimagining different aspects.

While slash fans might typically be understood as transformational fans, producer outreach to Supernatural fans and fan desire to collaborate with producers work to keep slash fans within the clearly defined boundaries of affirmational fans. For example, to return to the topic of shipping, fans are persuaded by vague producer promises of seeing Destiel in canon. Supernatural producers sidestep and direct questions on Dean or Castiel's sexuality, while fans patiently wait, displaying a trust that their patience will pay off. Supernatural's producers can be seen as encouraging an affirmational fan dynamic, endorsing fan activity and involvement (up to a particular point), in exchange for their support.

Supernatural fans are aware that their spaces are being monitored. Rather than a community operating on the margins or in the shadows as Bacon-Smith found in her study of the Star Trek fandom, Supernatural slash fans are constantly under producer scrutiny, and even more importantly, are aware of it. Destiel fans are increasingly positioned as collaborators by Supernatural producers. However, while their fan pairing is superficially supported by producers who are willing to encode queer desire into the subtext of the show and flirt with the idea in their interactions with fans, fans are actually disciplined by producers to remain within clearly defined boundaries in which homosexual desire is hinted at but never recognized. Fans that transgress these boundaries, such as those who push for an explicit mention of the Dean and Castiel relationship or dare to raise direct 
questions regarding subtext to staffers like Ackles are disciplined: both from those with authority, such as convention and production staff as well as from the fandom itself, who boo and police community behavior. This collaborative, affirmational fan culture potentially has consequences on other fan activities like fan fiction.

\subsection{Supernatural Fanfiction}

Supernatural staff has worked hard to develop a model of engagement with fans, from their use of social media to the strenuous convention schedule they keep. Jenkins, Ford, and Green note that engagement with a brand or fan community can influence the culture (172). How then, have fans reimagined the source material of Supernatural? What kinds of readings and interpretations of characters and relationships become popular within a fandom that has such a high level of access to the authors? I argue that in their fan fiction slash fans have largely remained within the boundaries of the show-- which in turn were themselves informed by the conventions of slash interpretive strategies. Supernatural's fan works that read a queer relationship between Dean and Castiel are consistent with the queerbaiting of producers. However, these stories often present a homonormative vision of sexuality rather than a transgressive one.

The fandom of Supernatural has generated a massive amount of fanproduced materials over the course of the show's nine seasons. To provide an exhaustive review of such a body of work would be impossible. However, it is a far more reasonable endeavor to examine some of the most recommended fanfiction in the fandom, as well as some of the existing tropes of the stories, which will help provide insight what kinds of stories and interpretations fans value. To better 
understand the common themes in fanfiction featuring the Destiel pairing, I've chosen to focus on three stories that are popular within the fandom and I believe exemplify a culture of homonormativity.

First, it may be useful to gain an understanding of the massive productivity of the fandom. The website Archive of Our Own, is a non-profit, run by the Organization for Transformative Works, created in 2007. The function of the group is to promote fan works and fan culture, created and run by self-described fans ("About the OTW" "About the Otw"). As a site generated from those within the community, it's very popular within many fandoms and houses a large chunk of fan-created works, including fanfiction. Of the top 100 fandoms on Archive of Our Own, currently about $75 \%$ of the fanfiction is slash, specifically slash taking place between two men. Out of all of the ships in fandoms reported on Archive of Our Own, the number two pairing is Dean/Castiel, or Destiel. The current total of Destiel fiction house on the website was sitting around 39,000 works.

For the Destiel shippers in the Supernatural fandom, there are some fanfiction titles that are considered classics. These are fanfictions that are highly recommended and generally well-known in the fan community. Resources run by power fans, such as destielfanfic.com, and The Collective (both are housed on the blogging site Tumblr.com) cultivate lists of fan fiction, compile reviews and links to stories, and serve as "tastemakers," recommending new and veteran fans to stories. In making my selection, I followed Robin Reid's method of considering works are "representative rather than unique" within the community and Dawn Heinecken's 
method of examining the most popular or "widely recommended" stories

(Heinecken 48; Reid 467) in order to discover stories that are most typical of the attitudes embraced by the fandom.

These three pieces of fanfiction are considered among the fandom classics, "The Mirror" by cloudyjenn, "Our Bodies, Possessed by Light" by Obstinatrix, and "The Day the World Went Away" by pyjamagurl. All are what are commonly considered long-form, falling between 24-60 thousand words. These pieces are particularly useful to understand the culture of homonormativity I believe exists within the Supernatural fandom, specifically those fans who engage in shipping Dean Winchester and Castiel. Because these stories are among the most popular and recommended, they communicate how the fandom popularly imagines these characters and their fan-constructed relationship and they are likely to influence new fans to view the relationship in the same way.

A common theme that these stories explore is the idea that Dean and Castiel are "destined" to be together. In fact, "The Mirror," is wholly devoted to this concept. The premise of the story surrounds a supernatural mirror that Dean finds during a hunt. It acts as a portal to other dimensions, transporting him to alternative realities. The alternative reality Dean Winchesters and Castiels come in many different configurations, ranging from female/male, female/female, and of course, male/male; however, in all configurations, they are romantically involved. As Dean works his way through alternative realities hoping to find his own, he gradually shifts from being a witness to these relationships to playing matchmaker, guiding 
the Dean and Castiel in that reality together romantically if they're not already.

Arriving back into his own reality, he wastes no time throwing himself at Castiel and physically demonstrating the love that he's finally acknowledged and accepted.

To think he almost missed this. Dean knows he won't let go of that what-if very easily. If not for a freaky mirror, Dean might have settled for less than love. Dean doesn't believe in soul mates, but after that trip, he certainly believes in the universe nudging you in the right direction. He can't wait to tell Castiel about all the bizarre worlds that brought him to this very moment. "I got the message, thanks," he says quietly. (cloudyjenn)

I would like to draw attention to the phrasing, "less than love" that the writer cloudyjenn uses. Soul mates or simply "meant to be" is the common construction of Dean and Castiel's relationship. Slash writers in Supernatural are utilizing the language of the show ("profound bond") and supernatural themes (destiny/fate/soulmates as dictated by a higher power), but are simply applying it to traditional slash conventions. In slash, "sexuality is linked...to a commitment embraced enthusiastically by both parties" (Jenkins 216). Despite Dean's womanizing, he's found his proper partner to settle down with, and thus begins his next phase of life in a committed, monogamous relationship. The respectability of monogamy tempers the "deviance" of a same-sex relationship.

"The Day the World Went Away," is bookended by a prologue and epilogue that depict shadowy figures, heavily implied to be God and an archangel, who are conspiring to demonstrate to Dean and Castiel how much they need each other. This is yet another example of the theme of destiny prevalent in Destiel fan fiction: the universe, a higher power, etc. is conspiring to enact what 'should be,' against 
characters who are 'too stubborn to realize.' The lesson in "The Day the World Went Away," comes from sending Dean five years into the future, where he is in an established relationship with Castiel; present Dean must learn that his true happiness comes from being with Castiel. The conflict here becomes getting Dean to accept not only his same-sex desire, but also his committed relationship. The story can only be resolved once Dean accepts the mantle of respectability, of a committed relationship with his predestined partner.

In order to create this idealized romance between Dean and Castiel, a common tactic is to dismiss all past romantic relationships. In the canon Dean has a history of being a womanizer and has one serious relationship with a woman, Lisa Braeden. "The Day the World Went Away" is set sometime in the sixth season, immediately following his break-up with Lisa. In the story Dean was unable to settle down with Lisa and quit hunting monsters, leaving her to return to hunting with his brother and Castiel. During a life-threatening monster encounter, Dean reflects, "he should be thinking of Lisa, that was the last person he was with, after all. But that's not the first person he thinks of, not the person he has wanted for years but thought he could never have. He wants Cas... It's sappy as all hell, but Cas fills a void that Lisa never could" (pyjamagurl). Rather than acknowledging that this relationship happened and simply ended, instead it becomes morphed into something "less than love," to borrow cloudyjenn's wording. As Jenkins notes, "If the characters have been causual about their previous sexual experiences, moving from one female lover to another, the discovery of the ideal male lover forecloses further promiscuity" 
(216). Dean is thus ushered into the respectable, sanctioned relationship with his soulmate.

In contrast, Castiel is often already firmly entrenched within these homonormative respectability politics. He serves as the role model, the end goal that Dean must accept by the end of the story. Typical of how fanfiction constructs the relationship, in this story, Castiel's feelings toward Dean are often constructed as more constant and developed. Castiel, unfettered by human heteronormative standards or gender dynamics is often all-too-conscious of his deeper feelings for Dean, "maybe he needs to reach out to this Dean more, finally cross that line between friendship and intimacy. It's scary, and he doesn't know how he should feel about altering the relationship he and Dean have" (pyjamagurl). He is left pining, resigned to accepting friendship rather than love from Dean, until the story unfolds and Dean is forced to sort out messy feelings he'd prefer to ignore for simplicity. While the conflict over whether to confess feelings is not particularly new, in these stories the it is framed as a question of whether or not Castiel should act in his capacity of role model, demonstrating the proper expression of desire Dean's working towards.

While the Destiel shipping fans may have constructed the relationship as "meant to be," they frequently attempt to preemptively address any obstacles that may arise, such as Dean's canonical expression of heterosexual desire. Dean is canonically shown to be a frequent consumer of heterosexual pornography with a noted interest in various waitresses and bartenders, and many writers work to 
reconcile his past womanizing and transition to a relationship with Castiel. This often comes in the form of a "gay panic" for Dean. This shock and reluctance to have a same-sex romantic and physical relationship is explored at length in "The Day the World Went Away." The story explicitly discusses Dean's refusal to be touched, even casually, by Castiel in the future as well as Dean's grappling with the fact that he left Lisa and a quiet life of domesticity only to continue hunting and develop a romantic relationship with Castiel, an angel in a male vessel.

A common way that writers overcome the "gay panic" felt by Dean is to remind readers of Castiel's non-human nature. In Supernatural, Castiel described himself once as a "multidimentional wavelength of celestial intent," which writers often use to emphasize that Castiel is not a gendered being ("The Third Man"). All three of these stories operate under this construction of Castiel as being without gender. If Castiel as an angel operates outside of gender, then Dean's same-sex attraction can remain label free, a potential avenue to resolve any crisis of identity. This panic is well noted in fanfiction, a step in slash Jenkins called the "masculine dystopia," and Rhiannon Bury the "queer denial" (Bury 90; Jenkins 209).

The idea that Dean is simply in love with Cas as an individual is the focus of "Our Bodies, Possessed by Light." The story explores what would have happened if Castiel's vessel had gotten destroyed in season seven. In the fanfiction, Castiel is forced to accept the only suitable vessel on hand, Sam Winchester, creating an unusual context for the two to discuss their feelings towards one another. In the 
story, a figure, later revealed to be God, asks Dean what kind of vessel he would choose for Castiel.

In detached moments, he sees Cas as he was, that blue-eyed man, his sharp nose, his tan, and although he knows Cas is not his body -- this whole thing with Sam can't help but have shown him that -- that is the way he knew Cas first, the way he sees him in his mind when all outside pressures are removed. Physically, historically, Dean's preferences run towards the same sort of leggy brunette that Sam prefers, some kind of shared genetic taste there, but Cas is outside of all that. Dean knows, rationally, that Cas has no gender, but he can't imagine him as a girl. Cas is that guy, Jimmy Novak. Cas is, in Dean's mind, the way he first saw him, pink mouth and mussy bed-hair under the power and the glory. (Obstinatrix "[Masterpost] Our Bodies, Possessed by Light ")

Dean, and thus readers, are disposed to view Castiel as an exception. That Dean wouldn't typically be found in a romantic entanglement with another man, and of course he really isn't, rather he's involved with an angel who happens to be housed in a male vessel. The story's driving conflict emphasizes this exception- centering on how Dean and Castiel navigate their changing relationship while Castiel is using the body of Dean's brother as a vessel. Over the course of the story, Dean, and thus the readers, are reminded that Castiel's physical body is not connected to his identityhis male body is a coincidence that Dean must overcome. Even after Castiel has his original vessel restored to him, Castiel is characterized with aspects of "gender blending," as termed by Elizabeth Woledge, "[juxtaposing] masculine and feminine traits," which although combines masculine and feminine traits in a character, relies on "conventional [gender] constructs $(54 ; 62)$. This fanfiction is remarkable for the way it neatly addresses Dean's identity crisis while simultaneously condemning the other most popular Supernatural slash pairing, Wincest (where brothers Sam and Dean are in a relationship). While Castiel might be housed in his brother's body, it 
serves to illustrate that Dean isn't attracted to Castiel's physical body, but rather Castiel as an individual. He is attached to Castiel's original vessel for its familiarity and through Castiel's own comfort with it.

Dean is the character most firmly rooted in his human masculine identity, as Destiel fans work to reconcile Dean's canon expressions of heterosexuality in their treatment of a developing romantic relationship between Dean and Castiel. Most writers and the fandom construct Dean as the one who "tops" when things turn sexual within the stories. While the fandom originally vacillated between either character acting as the penetrator, over time, the preference for "Top!Dean," (as styled by the fandom) has become more and more overt, while older fanfictions that do not demonstrate this model are criticized (Author Spotlight: Obstinatrix "Author Spotlight: Obstinatrix"). This preference for Top!Dean is present in these stories, as well. In two of the three, Dean is the penetrator when the two finally do have sex. "The Day the World Went Away," is the only story that has Dean received for the pair's first time together, which makes sense- in that story, Castiel functions as the role model and thus is showing the past Dean how they expressed desire in their relationship; this functions as a way of showing acceptable ways to express desire, which is tied to the monogamous, long-term relationship that Dean and Castiel are in.

Most of the works in the Destiel genre draw on what fans see as representative quirks that demonstrate Dean and Castiel's closeness within the show, such as Castiel's particular habit of staring, his lack of respect for Dean's 
personal space, and history of generally appearing whenever Dean calls. As Bury mentioned earlier, knowledge and fluency with the canon is paramount to fanfiction writers, the statement holding true within the Supernatural fandom as well. Over the course of the seasons, several habits have developed in Dean and Castiel's relationship that have translated to the slash genre.

As an angel, Castiel frequently displays his otherworldly nature and lack of humanity. Despite having spent years watching humanity and several years engaging with the Winchesters, there are some odd habits that he maintains. This includes staring, which accompanies nearly every single interaction Castiel has with Dean. The camera makes a note to linger in an extreme close-up, first on one and then the other, long after the conversation has ceased. There's typically a slight squinting thrown into the gesture as well, and it helps to underscore the characterizations of Castiel's obliviousness to innuendo, particularly in sexual situations ("Free to Be You and Me"). In many stories, Castiel's propensity for staring, especially at Dean, is viewed as yet another piece of proof of feelings between the pair. In "The Day the World Went Away," Sam points out to Dean

"I've seen how you look at him, how he looks at you...." Sam says carefully, "Didn't you notice how much Cas looked at you [when we first met]? Still looks at you?"

"Cas looks at everyone like that," Dean says, and he knows it's a lie as soon as he's said it. He can't think of a single instance in which Cas has looked at anyone with the same intensity as he does him. (pyjamagurl)

Eye contact becomes particularly important. Supernatural often uses it in service of queerbaiting, where eye contact, especially if extended, is frequently read as a sign of intimacy. Camille Bacon-Smith, in her work on slash interpretive strategies, notes 
the eroticization of the gaze in slash, "the eyes and eye contact can be interpreted as a display of intimacy" within a show, and thus, "fan writers lavish descriptive attention on the romance of eye contact" (Enterprising Women: Television Fandom and the Creation of Popular Myth 235). Supernatural undoubtedly taps into this history of fans coding the gaze as homoerotic, and it becomes replicated again in the Supernatural fan writings.

Another aspect from Dean and Castiel's interactions in Supernatural that resurfaces in fanfiction is the concept of personal space. In the show, it is implied that Dean has discussed this issue repeatedly, as Dean references past conversations whenever Castiel forgets, appearing within five inches of Dean's face with his typical greeting, "Hello, Dean" ("Free to Be You and Me"). Writers often interpret Castiel's staring and repeated invasions of personal space as Castiel attempting to subtly express his feelings (Obstinatrix, pyjamagurl).

The most notable idea that fanfiction writers utilize is the "profound bond" shared between Dean and Castiel which is demonstrated repeatedly through the series, especially when others try to contact the angel with no response, and moments later Castiel arrives at Dean's prayer ("The Third Man"). When Castiel resurrected Dean from Hell, the only mark on Dean's body was a raised handprint, presumably that of Castiel. In fanfiction, this is typically presented as a physical manifestation of this profound bond, sometimes acting as an erogenous zone.

The concept of the profound bond is one that feeds directly into the culture of homonormativity. It helps to serve as an easy explanation for Dean's non- 
heterosexual feelings. By couching the relationship in the language that Supernatural provides, the profound bond, writers channel the idea of true love, or soul mates, and distinguish the feelings and relationship of Dean and Castiel in ways that avoid any queer labels. Their fan-constructed relationship becomes deliberately divorced from a larger queer community, creating an entirely separate, clearly distinguished category of the "profoundly bonded" or soulmates. These characters are "destined" to be together, where forces such as the "universe," God, or other angels are all working behind the scenes to allow the pair to realize their unique situation. This destiny calls them into the respectable, monogamous relationship sanctioned by homonormativity- now that they've found their soulmate, they no longer have any justification for promiscuity. With the focus on Castiel's status as a being transcendent of gender, and Dean's status as his "righteous man" there is no room for connection to an LGBTQ community outside of the accepted gay marriage agenda.

It is clear then, that despite the traditional academic construction of slash as a queer, resistant space, the presence of slash alone does not make the fan activity resistant or queer. We must interrogate these spaces to discern the values and constructions that are being presented. The fan culture of Supernatural, consists of an affirmational fandom whose fan imaginings largely respects the boundaries set by the show producers. 


\section{"NOW PEOPLE WILL DEFINITELY TALK:" A CASE STUDY OF SHERLOCK AND ITS FANDOM}

\subsection{Sherlock Textual Analysis}

The story of Sherlock Holmes has an enduring legacy. From the character's first appearance in the late 1800s, Sir Arthur Conan Doyle's detective has taken on a life of his own, through fan activities, plays, movies, and television shows. The BBC's Sherlock has proven an extremely popular and well-received adaptation. The show stars Benedict Cumberbatch and Martin Freeman as Sherlock Holmes and John Watson, respectively. There have been three seasons to date, each consisting of three 90 minute episodes. Sherlock was created by Steven Moffat and Mark Gatiss, with the writers adapting many of Doyle's original stories for a modern-day setting.

This case study of Sherlock and its fans has several goals. First, I will look at the text of the show and producer fan interactions to demonstrate how producers court fans through the practice of queerbaiting. I will show how writers code Sherlock with a homoerotic subtext in ways that appeal to fan sensibilities even as producers' antagonistic communications with fans overtly deny the show's queer potential. I have examined all episodes through season three of Sherlock, with a particular focus on how the relationship between Holmes and Watson is built. I have highlighted moments that fans of Johnlock (slash pairing between Holmes and Watson) often emphasize in their own readings of the show. To do this, I examined 
series 1-3, which consist of 9 episodes (which are 90 minutes in length). Second, I will focus on fan resistance to such denials of homoerotic subtext. I will show how some fans seek to resist producer framings of the text and "call out" to the producers the problem of queerbaiting. I will also analyze works of Sherlock, considered "classics" within the fandom, arguing that Sherlock fans have crafted fanfiction that that resists the culture of homonormativity. The co-creator of the BBC's Sherlock, Moffat acknowledges that Sherlock is about the partnership of Holmes and Watson. Moffat has repeatedly stated that, "the friendship between Holmes and Doctor Watson is right at the heart of [the story]" (Ittner). However, queer readings are enabled by the producers' foregrounding of themes designed to appeal to fans. These include an explicit acknowledgment of the potential for queer relationships within the canon, a practice that uncovers the homoerotic subtext of the buddy story and simultaneously nods to fans' subversive practice of queer readings. In addition, queer readings are enabled by the level of intimacy depicted between the two characters on the show, such as Holmes' fixation on Watson, as well as Watson's sentimental, and favorable view of Holmes.

Sherlock producers' naming of homoerotic possibilities is one way that queer readings are enabled. For example, the pilot episode introduces the characters and their relationships to the audience. "A Study in Pink", which depicts Holmes and Watson settling into their roles as flatmates and collaborators, foregrounds the possibility of a queer relationship. Every person who meets the pair assumes that this is a blossoming romantic relationship. Mrs. Hudson, the landlady, assumes the roommates will only be requiring one bedroom. Later, as Holmes brings Watson to 
investigate a crime scene (their first together), Detective Sergeant Sally Donovan questions Watson, "You're not his friend. He doesn't have friends. So who are you?" ("A Study in Pink"). Donovan's words imply that while Holmes doesn't have friends, a boyfriend is another matter entirely. Mycroft Holmes, similarly suggests a sexual relationship between the two, noting "since yesterday you've moved in with him and now you're solving crimes together. Might we expect a happy announcement by the end of the week?" ("A Study in Pink"). Later in the episode, a restaurant owner refers to Watson as Holmes' date, adding a candle to their table with a flourish. Finally, the characters broach it themselves,

WATSON: You don't have a girlfriend, then?

HOLMES: Girlfriend? No, not really my area.

WATSON: Oh, right. D'you have a boyfriend? Which is fine, by the way.

HOLMES: I know it's fine.

WATSON: So you've got a boyfriend then?

HOLMES: No.

WATSON: Right. Okay. You're unattached. Like me. Fine. Good.

HOLMES: John, um ... I think you should know that I consider myself married to my work, and while I'm flattered by your interest, I'm really not looking for any ...

WATSON: No. No, I'm not asking. No. I'm just saying, it's all fine.

As the audience is repeatedly reminded in this scene, being gay is "fine" and the characters don't directly rule out the possibility in this conversation. Some, such as the Sherlock writers, view Holmes' statement of being "married" to his work as an attempt to communicate his asexuality, an identity which departs from normative constructions of heterosexuality (Lavigne 18). Carlen Lavigne sees this exchange as 
an example of Holmes being placed in "the realm of permanent possibility; he is assuredly queer... and he could be gay, straight, bisexual, asexual or pansexual. He does not commit himself in any way" (18). Such openness appeals to fan because it allows them to create their own conceptions of desire- particularly Holmes' undefined sexuality.

In addition to comments by other characters, the behavior of Watson and Holmes also point to their strong feelings for each other. For example, in a conversation with Mycroft, Watson pays more attention to the texts he's receiving from Sherlock than to the man he's speaking with, indicating the primacy Holmes already holds in Watson's life. When Mycroft Holmes offers Watson money to act as an informant on Sherlock, Watson emphatically turns down his offer, despite the fact that he has money problems. Their exchange demonstrates the deep loyalty Watson already has for Holmes. That loyalty is strikingly similar to the "enthusiastic commitment" that characters in slash relationships display- the obvious seeds are present and ripe for a queer reading (Jenkins 216). Through Watson's loyalty and praise of Holmes, the audience perceives that Watson sees Holmes as desirable and compelling, opening up a queer subtext ready-made for slash fanfiction reimaginings.

Watson's newfound loyalty does not go unanswered, as Holmes demonstrates his own affinity for his new partner. Despite referring to himself as a "high-functioning sociopath," Holmes repeatedly shows dedication and consideration to Watson in other episodes in the series. In "The Great Game," 
Moriarty presents puzzles for Holmes. Each comes with a deadline, and involves the use of kidnapped innocent citizens: Moriarty "speaks" to Holmes by having the hostages read his words to Holmes over the phone and if Holmes is unable to solve the puzzle, the explosives strapped to the hostages' chests will go off. After Holmes receives the first phone call announcing the "game", Watson is outraged at Holmes' apparent callousness and lack of compassion. When a hostage loses her life, he asks Holmes if he cares about these. Holmes' only response is, "Will caring about them help to save them?... Then I'll continue not to make that mistake" ("The Great Game"). However Holmes' earlier lack of compassion contrasts with his reaction at the end of the episode, when Watson becomes one of Moriarty's hostages. Here, Holmes is willing to trade British military secrets for Watson and he frantically tears the explosive vest off of Watson in a rare display of emotion. Holmes' previous statements about his lack of caring obviously do not apply where Watson is concerned. Holmes quite obviously cares for Watson and is concerned for his personal safety. This emotional moment between Holmes and Watson, coupled with the fact that Holmes literally tears off Watson's clothes before the camera cuts away from the pair to an empty pool is read as a queer moment by many fans. Fans wonder what else happened after the camera cut away from the pair in the empty pool. Again, Sherlock producers seem intent on providing writing prompts for slash writers. Near-death experiences and other injuries are often the starting point of slash fiction, reminding the characters "of the fragility of their relationship and what would be lost," at one of their deaths (Jenkins 209). Just as they presented the inexplicable sudden loyalty between Holmes and Watson, the producers ended the 
series on a cliffhanger that would be considered an admirable start to any hurt/comfort slash story.

Aside from the literally tearing off Watson's clothes, there are other ways we see the primacy of Watson in Holmes' life within Sherlock, expressed in ways more befitting of a romantic partner than a friend. The deep-seated nature of Holmes' concern for Watson is emphasized when in the finale of the third season, "His Last Vow" Holmes is shot on a case. The next sequence shows Holmes retreating inside his mind, where he calculates the life-threatening severity of his wound and his internal battle to either submit to death or "fight" for life. Outside of Holmes' mind, viewers see Holmes on the hospital operating table, the monitors displaying a flatline indicating his death. Holmes rallies as a voice in his mind states, "Mrs. Hudson will cry; and Mummy and Daddy will cry .... and The Woman will cry; and John will cry buckets and buckets. It's him that I worry about the most. That wife! You're letting him down, Sherlock. John Watson is definitely in danger" ("His Last Vow"). Here, we see how Holmes places Watson above even his family, convinced that Watson is the one who will be impacted the most by Holmes' passing. Holmes' mental exclamation of "That wife!" is rife with disgust, carrying implications to many slash fans of Holmes' distaste for Watson's romantic relationship, arguably because his wife is occupying the primary spot that Holmes had previously enjoyed. The consideration and care Holmes has for Watson saves both of their lives. Holmes regains consciousness and later warns Watson of the danger he's in. We see here that Holmes indeed is able to care for another person, despite his denials. This is 
another way that producers code the text for a queer reading, indicating a growing intimacy between the two characters.

Holmes' disgust for Watson's wife reflects what Lavigne describes as a feeling of "possessive jealousy" (18). Lavigne identifies Holmes' interference with Watson's first date with a woman in "The Blind Banker" as another example of Holmes' possessive jealousy. He is surprised that Watson is going on a date, rather than spending the evening with him investigating. When Watson explains a date as an event "where two people who like each other go out and have fun" Holmes' responds, "That's what I was suggesting" ("The Blind Banker"). His response once again reveals the homoerotic subtext of their relationship. This homoerotic potential is enhanced when Holmes ends up joining Watson on his date at the circus. Throughout the encounter, Holmes leans forward, explaining the circus acts quietly in Watson's ear while ignoring Watson's date the entire time. His insistence on accompanying Watson suggests that Holmes feels entitled to Watson's time. Holmes views himself and their activities of crime-solving as more compelling and more important. Here, Holmes deliberately interrupts Watson's date, one of the first visible activities of heterosexuality we've seen in the series, and insists that their partnership is more important. Holmes is conducting himself as the primary focus in Watson's life, a place that a romantic partner traditionally occupies. Elsewhere, Holmes appears jealous of the attention Watson pays to another man, Major Sholto, who, like Holmes, is known for being unsociable and difficult. His jealousy over the fact that Watson describes Sholto as "the most unsociable man he's ever met" ("The Sign of Three") indicates his anxiety that perhaps Watson has a "type" of man he's 
drawn to, and that Holmes is not unique. Holmes appears irritated he does not hold the same position of primacy in Watson's life as Watson does in his own. Holmes' jealousy towards both female and male rivals for Watson's affection shows the centrality of their relationship to him and suggests the depths of his desire. In addition, when Holmes interrupts him on his date, Watson does not choose the heteroromantic, He runs off to assist Holmes in the investigation midway through his date, choosing the homosocial and edging close to the homoerotic through trading his female interest for Holmes.

Holmes displays a rare vulnerability when he's with Watson, giving the other man a substantial amount of power over the detective. Watson is meant to be "representative" of society in Sherlock; we see Holmes and understand this world through Watson (Toadvine). April Toadvine views Watson in part as reflecting social norms within the show, reminding Holmes of societal expectations of manners and empathy (55). Watson often acts as a moral compass for the audience and the detective. From this position, Watson slowly exerts a greater influence on the detective, forcing him to acknowledge social niceties and societal norms. Holmes customarily interacts with people to get whatever information he can by any means necessary, including emotional manipulation, and often shows a disregard for the safety or emotional well-being of others, unless that person is Watson. In contrast, Watson continually reminds Holmes to consider their clients as people, to be mindful of the timing or appropriateness of his remarks on a case. In "The Hounds of Baskerville,"Watson's humanizing effect on Holmes is palpable. Holmes, who has never cared how he is perceived, cares about how Watson views him. During the 
case, he snaps at Watson, insisting that there is nothing wrong with him despite being clearly rattled by an encounter in the woods earlier. Although earlier he had told Watson "I don't have friends," he later explains that he was experiencing doubt in his abilities, a terrifying idea for the detective. He corrects his previous statement to Watson, "I don't have friends. I've only got one" ("The Hounds of Baskerville"). Later, Holmes explains his actions during the case again to Watson, who points out that Holmes actually made a small mistake in his deductions. In a rare moment of humility for the self-important detective, Holmes admits that he "got it wrong," on one aspect. Throughout "Hounds of Baskerville," viewers are treated with a Holmes at his most vulnerable, admitting fear and fallibility, even if this weakness is only shared with Watson in private. Watson has already begun to effectively "humanize" Holmes, ("The Great Game"). Through Watson's consistent praising and the positive perspective he has of Holmes and his abilities, we see Holmes soften in his treatment of others, responding to Watson's corrections at least partially, from actually allowing potential clients to explain their case without outright dismissing them, to his rare demonstration of tact in refraining from commenting on other's appearance. Holmes' newfound humanity is further magnified in the third season. In "The Sign of Three," during his best man speech at Watson's marriage, Holmes notes the contrast between Watson and himself- how rude and inconsiderate he is to Watson's kindness and bravery. He cautions the assembled crowd, "should any of you require the services of either of us, I will solve your murder, but it takes John Watson to save your life. Trust me on that - I should know. He's saved mine so many times, and in so many ways" ("The Sign of Three"). Watson's humanizing 
importance to Holmes is explicitly underscored here. Holmes, despite holding the "cold" logic of reason above all, has learned from Watson about the strengths of compassion. In the speech, Holmes, in a watered down moment of possessiveness, asserts that the pair of them are necessary to each other, and their complementary strengths will only help as they continue their investigative work. Like the Kirk/Spock of old, the Holmes/Watson pairing may appeal to fans because they can also "[represent] not a bonded pair, but a divided self... two humans once whole separated and ever seeking their other half" (Falzone 256). Canonically, Holmes and Watson need each other, only achieving their true self as a unit.

As opposed to Supernatural, Sherlock manages to squeeze in explicit assumptions of Watson and Holmes' relationship status at every opportunity, or as Lavigne terms it, makes "open acknowledgement of its queer possibilities." As Lavigne notes, the subtext of Sherlock remains insistent, "we return to [Holmes/Watson couplehood] again and again, never quite letting the possibility of homoerotic tension fade," (Lavigne 20). Lavigne's optimism comes from the fact that Holmes and Watson can be read as queer by fans, and that the show leaves that possibility open.

However, as Lavigne notes, Sherlock's follows the "buddy cop pattern," which bears a strong resemblance to the intimate friendship of the bromance, narratives that are often scrutinized for homoerotic subtext (16-17). In the bromance "two men share professional and domestic intimacy... form two halves of one powerhouse whole, but [their] frequently looks and physical proximity must 
constantly struggle against their own romantic implications" (Lavigne 17). Peter Forster notes that bromance has "two interlocking preoccupations," the first is managing the conflict between homosocial and homoerotic in the primary male/male relationship, and the second is managing the conflict between the homosocial and heteroromantic, the female partners of the men involved (Ch. 7). Like the bromance, the buddy cop also "include tertiary girlfriends, former wives" and uses "homophobic humor in order to repeatedly (re-)establish the male protagonists' heterosexuality" (Lavigne 17). Bromance and the buddy cop rely on heterosexuality to work, because they explicitly deny a gay identity.

Sherlock follows many of the patterns of the bromance, like the playful relationship between the protagonists which constantly recalls the possibility of same sex desire; however it's denial of gay identity is complicated by Holmes' stated lack of romantic interest, leaving the only substantial relationship that fans see taking place between Holmes/Watson. According to Lavigne Sherlock has a "playful willingness to highlight and explore its own 'bromance' tropes, creating a persistent, open tease of queer possibilities" (13). Like Lavigne, many fans feel that the demonstration of male affection in Sherlock goes beyond friendship. Such readings are not surprising given the text and subtext of the show, which seems designed to appeal to fan desires and feed fan activity. However, because Sherlock writers and producers still establish the characters' heterosexuality in the canon and limit explicitly queer representation to subtext and possibilities, rather than an explicit statement, they are practicing queerbaiting. 
In addition, as Lavigne herself notes, queer possibilities are frequently used as a punchline within the show. Bromance and the buddy cop preserve heteronormativity, by categorizing the homosexual as "the outsider, the Other" whose "Otherness can serve to energize homosocial bonding, most obviously by inviting homophobia into it" (Forster Ch. 7). The ways that Sherlock presents the idea of Holmes and Watson in a queer relationship as a joke turns the idea of a queer identity and sexuality into a joke itself. In addition, despite all of the ways that the show implies the potential of a queer relationship -in both the canon and the subtextual implications of their interactions, Moffat and Gatiss are still attempting to solve the bromance's "conflict between the homosocial and homoerotic," attempting to convey the "male-male desire" in the spirit of friendship rather than attraction (Forster Ch. 7). To counter a reading of the relationship as queer, they give Watson a fixed heterosexual identity, signified through his multiple dates, his repeated corrections that he is straight and not in a relationship with Holmes, and the ultimate signifier of heterosexuality- his marriage to a woman. For many fans, though, Watson's protests are directly contradicted by his actions that always bring him back to Holmes.

For scholars like Lavigne the "flexibility of [Sherlock's] sexual paradigm," presents an optimistic view of sexuality within the show (22). Others, including myself, take a different view: Sherlock is queerbaiting fans, allowing audience members who respond to the subtext of intimacy presented to hope for representation, while simultaneously refusing to commit to those possibilities in 
text. Many fans are increasingly calling out these queerbaiting tactics, demanding accountability from producers for irresponsible treatments of queer characters.

\subsection{Sherlock Fan-Producer Relationship}

In this section, I trace the producer-fan interactions to demonstrate that Sherlock creators have developed an antagonistic relationship with fans. This antagonism, coupled with the distrust of producer input, has made it impossible for fans to participate as affirmational fans. I believe that this climate of uncertainty and antagonism allows Sherlock fans to occupy a transformational space, since they are unable to participate as affirmational fans. Sherlock producers do not attempt to mirror fan sensibilities, insisting that their product is fueled by their own vision as creators.

To assume that the producers of Sherlock are unaware of the homoerotic subtext within the show would not just be a large stretch of the imagination, but it would also be patently false. The producers have said their version is a homage to The Private Life of Sherlock Holmes, in which Holmes can be read as having a gay identity and which both Moffat and Gatiss enjoy. In addition, the fact remains that as self-professed fans themselves, they are very much aware of common fan activities, such as fanfiction and shipping. Sherlock producers have also fully embraced transmedia engagement, creating Watson and Holmes' blogs for fans to sift through, along with comments from the characters on the posts, releasing behind-the-scenes specials to encourage fan discussion, etc. Sherlock producers explicitly focus on, and thereby sanction, affirmational fans. They encourage the investigative work of fans, such as the monumental theorizing on exactly how 
Holmes survived jumping off the roof at the end of season two, while discouraging the transformative work that fans bring to reinterpreting Holmes' interpersonal relationships and sexuality.

We can see this tendency to legitimize affirmational fans through the strict boundaries Sherlock producers create between themselves and fans. These strict boundaries prevent the collaborative aspect found between Supernatural producers and fans. The relationship between producers and fans of Sherlock is much different than that of Supernatural. Sherlock fans largely experience a more traditional means of interacting with show staff. The Sherlock cast and crew do not faithfully attend dozens of conventions, and they do not participate in weekly live-Tweeting sessions with fans while a new episode is airing. Panels at large venues like Comic Con and interviews with reporters are the most common way that fans can reach the staff of Sherlock. Cumberbatch and Freeman have no social media available to fans, Moffat has deleted his Twitter, leaving Gatiss as the only available person for fans to communicate with outside of predetermined hours of conventions and media interviews.

In this section, I'll discuss the Moffat and Gatiss official stance of the show, in which they have stated repeatedly that Holmes and Watson are absolutely not gay, despite coding Sherlock with a staggering amount of queer subtext and tropes right out of traditional slash fanfiction. I will also detail their reactions to fan inquiries, as their responses work to consolidate their own power as producers and owners of the text, dismissing fan-generated queer readings. I will also discuss notable fan 
responses in order to show how fans are resisting producer meanings by calling them out on their queerbaiting practices.

Mark Gatiss has maintained the official stance of Holmes and Watson as "not gay." When asked by a fan at a Comic Con panel in Mumbai if he had to "resist the temptation" of writing Holmes and Watson as gay, he dismissed it as "not a temptation" (24Shining Stars). He argues that people often see successful shows as needing to "carry a torch" or "fly a flag," meaning that they should take a stance on an issue, in this case, queer representation of a same-sex romantic couple. Gatiss states that the constant assumptions of a relationship by the other characters inshow serve as Moffat and Gatiss' nod to The Private Life of Sherlock Holmes, which depicts Holmes as gay and is a version of the Holmes' story that both creators love. Gatiss continues, "but it is a joke. Not to belittle the idea that they could be [gay] but in our version, they are not." He stresses that Holmes isn't incapable of feeling emotion or desire, and isn't asexual, but rather sex is something that he chooses to reject to focus on his work (24Shining Stars). Gatiss emphatically states, "if we had an agenda of making Sherlock and Dr. Watson an openly gay couple, that's what we would have done. But that's not what we're doing. I'm very happy everybody thinks what they like, but it's never going to happen" (24Shining Stars). Gatiss' use of the word 'agenda' is interesting; he demonstrates awareness that queer representation would be a political move. But for Gatiss, adding queer identities in a successful show would be flying a flag, not a legitimate story decision. However, this explicit distancing is itself political, a conservative move that boxes sexuality and confines it to identity politics that have a time and place that have no place in the narrative 
unless it's as a plot point. Incidental characters can be gay, jokes can be made to demonstrate "progress," but a queer identity for a main character would have different, "political" issues that apparently don't fit in Sherlock. His answer explicitly acknowledges that queer identity is being played as a joke, a teasing homage to an earlier movie interpretation. Sherlock's creators are adamant that these men are absolutely not gay, despite what the text suggests.

Moffat further expands on Holmes' sexual identity, framing it not just as "not gay," but as a matter of abstinence. When asked by a reporter in a promotional story about solving the "problem" of Holmes' sex life, and determining the precise sexual identity of Holmes, Moffat states, "There's no indication in the original stories that he was asexual or gay. He actually says he declines the attention of women because he doesn't want the distraction...He wouldn't be living with a man if he thought men were interesting" (Jeffries). Moffat doesn't view Holmes as lacking sexuality, as some fans view the detective. He rejects the possibility of asexuality, claiming Holmes' is the "choice of a monk, not the choice of an asexual" because there's "no tension in that, no fun in that- it's someone who abstains who's interesting" (Jeffries). Aside from Moffat's problematic invoking of choice and dismissing asexuality as boring, his message is resoundingly clear: Holmes is not gay. Moffat further underscores his point when sharing his understanding of The Woman, Irene Adler. To Moffat, the only reasonable explanation for Holmes' fascination for the only woman to beat him is that "he fancies her," because there are "better villains" that he could play and beat, but The Woman's importance is only justified because Holmes "fancies" her (Rosenberg). Moffat frames Holmes as heterosexual. 
When asked again recently at the 2013 BAFTA red carpet about the relationship between Holmes and Watson portrayed on the show, and its potential for a same-sex romance, Moffat stated, "[Fans] are mostly projecting it onto the show themselves... People have been doing that with Sherlock Holmes and Dr. Watson long before we took it over. So in fact our biggest reference to it was to explicitly deny that it was happening, but people have their own fantasies and that's fine, that's good" (Viva). Moffat and Gatiss are admitted fans and have an understanding of fan activities, and specifically, they understand the fan activities that are circulating around Sherlock, including the slash pairings of Holmes and Watson. Moffat shifts the responsibility of a queer reading onto the fans- implying that it originates from them, even though the first episode and most of the show includes assumptions of a queer sexuality and allusions to it by other characters. Moffat seems to be building his denials into the text, having Watson insist again and again on his- and subsequently the show's- heterosexuality.

Despite their backgrounds as fans, producers deny an awareness of fan activities. For example, many fans feel season three trots out fandom jokes and speculations, particularly via the character of Anderson and his conspiracy group, who becomes a stand-in for the fandom. The show plays out several theories of how Holmes survived the rooftop jump; one takes the heterosexual pairing of Holmes/Molly, showing them passionately kissing after he fakes his death, another speculates that Holmes and Moriarty planned the entire suicide, before they too lean in to kiss (although the camera cuts away before a queer expression of desire is actually shown). 
Asked by fans at a Q\&A session at Mumbai Comic Con about the number of fan fictions producers read in order to include all the nods to fans in the season, Mark Gatiss stated, “we don’t read fanfiction” (Stars). His response met with gasps from the crowd, signaling their disbelief- for fans, season three was filled with too many conventional Sherlock fan imaginings to be completely coincidental. When a fan asked about a specific moment that seems to address fan theories about how Holmes survived a cliffhanger episode, Gatiss laughed and said, "You don't have to read [fanfiction] to be aware of what people think" (Stars). Gatiss' statement that the producers don't need to engage with fandom to understand it feels disingenuous. It is because Moffat and Gatiss were fans participating in fandom that they understand it. Both men grew up writing their own Doctor Who and Sherlock Holmes fanfiction, although the word Gatiss uses is "stories," but he acknowledges that they're the same (Stars). Moffat has moved from "hobbyist"' to "paid 'expert'" selling back "fans' values and authenticities" to audiences today, a position of power that he's able to utilize precisely because of his "immersion in fan culture and its forms of knowledge and competence" (Hills 40). Despite their awareness of fandom, they downplay their knowledge and experience with fan culture to preserve their authority as producers.

One way the Sherlock producers preserve their authority is how they present themselves as having final control and say over the meaning of the show. At the finale of season three, show creators and some cast members were present at the BAFTA screening and participated in a Q\&A afterwards. Moffat was asked, "Do you think that future of television is more of a combination of an interaction with 
fans?" Moffat's response is interesting, demonstrating a rather traditional imagining of power despite his own roots in fandom himself.

It's not how it works, it truly isn't. The creative response of fans is amazing, it's extraordinary, and it's not an exaggeration to say it's the cradle of the next generation of television and fiction producers. It's hugely important, but it's a one-way thing. What happens is - and I was part of this, I am part of this - is that you see something you love, you start doing your own version of it. Then you start disagreeing with the actual version and think 'my version's better', and then you discover you've made something entirely different and you go off and do your own thing.

I find it exciting and thrilling and wonderful that you get that creative response to a TV show. It's how I began - I responded to Doctor Who and Sherlock and look how far I've come! [laughter]. I find that exciting but no, interaction with the fans is not how it works because in the end they've got to cut loose from the mother ship and do their own thing, and they will, they will. I think it's incredibly exciting but no, we don't interact with the fans apart from saying 'hello' and how much we love them. (emphasis mine, Mellor)

Moffat's conceptualization of power is "a one way thing," and that Sherlock producers are the sole possessors of it. The producers, who are former fans who have now been sanctioned as authors, are actively delegitimizing fan perspectivesperspectives they once held themselves. Moffat isn't afraid to use his new, corporately-sanctioned voice to silence fans who "forget their place" in this hierarchy.

One way that fans are silenced, beyond the more limiting nature of how and when fans can contact producers, is the nature of producer interactions with fans. Steven Moffat has acquired a reputation amongst fans for being antagonistic and flippant when questioned about his work, particularly when it concerns the representation of women or LGB characters. An extended exchange on Twitter 
between Moffatt and Doctor Who fans before Moffat deleted his account best exemplifies this attitude. The tweets in question however, were captured by the STFU-Moffat blog, preserving them for future records. When asked the Doctor's position on gay rights, initially Moffat is flippant and jokes that the Doctor has little time to consider such issues, but if forced to, would be irritated that gay marriage would be a point of conflict. This is a remarkably similar perspective to his view of Holmes who is too "busy" and unwilling to engage in sexuality in favor of his work. When fans pointed out the presence of Jack Harkness and River Song, both characters known for their open sexuality, Moffat characterizes them as "happily bi" (STFU-Moffat "Let's Look at the Twitter Thing from the Beginning"). This pronouncement only draws more attention from fans on Twitter, an indication that these characters weren't so clearly defined, despite Moffat's view. One fan asks after the Doctor's sexuality, thanking Moffat for "all the bisexuals," since bisexual representation is lacking on television, and another fan expressing excitement that River's bisexuality was confirmed (STFU-Moffat "Let's Look at the Twitter Thing from the Beginning"). Moffat responds that bisexuals aren't acknowledged on television because they're having, "FAR TOO MUCH FUN," telling the fan, "You probably don't even watch cos you're so BUSY!!" mocking the fan's sexuality by drawing on tired stereotypes that bisexuals are especially promiscuous because of their sexuality. Meanwhile he tells the other fan that he didn't understand her excitement, since he felt River's sexuality was well-established in the show (STFUMoffat "Let's Look at the Twitter Thing from the Beginning"). Even in these positive conversations with fans who are praising his work, Moffat is unable to have a 
substantial conversation regarding sexuality, alternating between spouting stereotypes about hypersexual bisexuals and dismissing the fans' excitement over a point he considers too obvious. When asked directly about how effective River was for bisexual visibility, Moffat responds with a series of question marks, and then questions, "When did I say I thought I was contributing to bisexual visibility?? Please stop being rude to me, you have no reason to be" (STFU-Moffat "Let's Look at the Twitter Thing from the Beginning"). At the first hint of a critical fan discussion, Moffat retreats, declaring her questions rude. This is a silencing tactic, allowing Moffat to avoid further discussion about sexuality- a topic some fans have long noted is a problem in his works. Later, Moffat explains where River's bisexuality is stated in the show (through implications and throwaway lines) and the fan thanks him, only to find herself blocked on Twitter by the writer later, no longer able to view his tweets or interact with him on the site. The fan who dares to critique Moffat finds herself literally silenced, as Moffat refuses to engage in critical discussions. Moffat, it seems, has a habit of viewing sexuality as too time-consuming, especially if one isn't monosexual, and prefers glibness over a substantive conversation with fans.

This Twitter encounter is an excellent example of the way Moffat communicates with his fans. His answers are largely flippant, seemingly dismissive of the amount of investment fans may have in the show, especially fans with marginalized identities looking for others like them in the media. These fans began the conversation by seeking more information on the show and characters that they follow. For some fans, Moffat's answers caused serious concern and these fans took 
the opportunity to respond to his statements and point out his historically mixed treatment of sexuality in his shows. Moffat uses queer sexuality as the punchline in his shows, and his humor carries over to social media interactions. Queer folk are still the butt of the joke, and Moffat will always have the final word. He's quick to end conversations if he encounters any fan criticism of his work, such as in the encounter described earlier. His aggressive silencing tactics bespeak of his insistence on preserving his creative vision. Moffat is taking pains to make his producerly authority unassailable. Moffat ultimately deleted his Twitter in September 2012, a few months later, with his wife stating that it was proving to be a distraction from work. Many fans speculate that Moffat exited Twitter because of his frequent "clashes with critics," especially when considering one of his final tweets from the account, "Forgive my ignorance - is there a way to limit who can follow and Tweet you?" (Pantozzi; Baker-Whitelaw). Since deleting his Twitter, he has chosen not to return to the website, communicating to fans only through more traditional channels, media interviews, commentary, and designated panels at large conventions like Comic Con. Moffat is dismissive of fan readings, and interpretations that find a queer subtext, and ignores any fans who disagree.

It is apparent then, that Sherlock fans do not have the same opportunity as Supernatural fans to reach out and hear back from the show's producers. When producers do interact with fans, it is in largely restrictive, antagonistic terms, which I believe has a correlative effect on the fandom. Fans' antagonistic interactions with producers lead them to resist the producer-authorized narrative and producerly authority. In particular, many fans question the truth of Moffat's words. Moffat's 
antagonistic relationship with fans has caused them to read him as an unreliable narrator. Referred to as "Rule 1: Moffat lies," a play on a line from Doctor Who, Moffatt has prompted an unusual level of distrust among fans seeking to solve the puzzles often found in his plots.

For example, at the premiere of season three, he was asked by an interviewer if Moriarty was "definitely dead," a fair question since Holmes had just been revealed to have faked his rooftop suicide, Moffat "exasperatedly" stated, “They did not fake suicide at each other. Imagine how stupid you'd feel if you bumped into each other [he mimes their exchange, 'what, you too?']. He's dead." Moffat's assertions were disproven in the finale of season three, which showed Moriarty's return (Harvey). Such strategies are consistent with Moffat's own selfpresentation, as he himself has stated, "I lie repeatedly and continually. It's by far the best way of communicating" (Martin).

Moffat's lying violates fan expectations rooted in the transmedia nature of the show. Sherlock is a hyperdiegetic text, characterized by its references to a "vast and detailed narrative space" much of which is not directly seen in the show (Hills 138). In Sherlock, for example, characters refer to cases that viewers haven't witnessed and the fan-accessible blog of Dr. Watson has a comment section used only by other characters. Moffat has built a world for fans to enjoy "display[s] such a coherency and continuity that it can be trusted by the viewer," a self-contained world that seems to promise that if fans are diligent viewers, they may be able to decipher the plot's puzzles themselves (Hills 138). Johnson notes that 
"hyperdiegesis provides audiences with constant, trustworthy, supportive environments" that enable fan practices like speculation and fan fiction (286). However, when the hyperdiegesis can no longer be trusted, as for example, by producer lies which disrupt the coherence and continuity of the textual world, fan activities are themselves threatened. Moffat has constructed a world where the fans are only seeing particular moments. However, as fans attempt to "decipher" these plot points and perform in sanctioned ways as an affirmational fan, they must then consider all pieces of information as evidence, such as Watson's blog, and producer clarification, such as when Gatiss confirmed that Milverton was Holmes' first kill. This cannot be accomplished if fans cannot trust the word of the authors. Sherlock producers are encouraging and attempting to cultivate affirmational fans, however, they consistently undermine the hyperdiegetic text that affirmational fans need in order to perform the investigative tasks set before them. The producers, because of that distrust, are actually blocking fans from being able to occupy that affirmational space.

In the face of this, or because of this, some fans remain doggedly persistent in their interpretations of Holmes/Watson romance. Within Sherlock fandom, mentions of TJLC arise periodically. TJLC refers to 'The Johnlock Conspiracy,' a theory extensively noted by a fan under the username 'loudest-subtext-in-television' on Tumblr. The basic idea is that the showrunners Moffat and Gatiss have simply repeatedly lied about the status of Holmes and Watson's relationship like they've lied about the plot in the past. These fans are not only responding to the homoerotic subtext of the show, but also the work of the producers, both within and outside of 
Sherlock. Proponents of TJLC believe that Sherlock producers have always intended Holmes and Watson to end up in a romantic relationship. Fans support this perspective with a staggering amount of documentation. They highlight a working group that BBC commissioned to research the status of LGB portrayals on the network and with audiences, occurring at the same time that Sherlock's pilot was being reworked to the current 90 minute format (loudest-subtext-in-television). The reports documents how the $\mathrm{BBC}$ was interested in developing LGB content that is "culturally iconic" and committed to "authentic portrayals of LGB identity," which audiences are interested in as well (loudest-subtext-in-television). TJLC fans pair this knowledge with the creative history of Moffat and Gatiss. The latter has repeatedly revealed a character as queer halfway through a book to avoid having the work labeled as a "LGBTQ" genre piece, such as in the spy story, The Vesuvius Club (loudest-subtext-in-television). Fans point to how Moffat has created multiple incarnations of Holmes and Watson, in other stories. An example of this is found in Doctor Who, in the lesbian couple of Madame Vastra and Jenny. They observe how Moffat and Gatiss have repeatedly stated their appreciation for The Private Life of Sherlock Holmes as well, considering it one of the "best" and "only genius film," which depicts the detective as gay (qtd by loudest-subtext-in-television). Fans' knowledge of this background, along with Gatiss' history of declaring characters as gay in the midst of the work, give some fans reason to hope that Holmes and Watson's relationship in Sherlock will be made explicitly gay.

Their determination to reject Moffat and Gatiss's explicit denials that Holmes and Watson are gay reveals fans' resistance to producers' stated goals. Moreover, 
this insistence stresses fans' activity and ability as textual readers. TJLC fans represent themselves as simply able to read the truth of the producer's intentions. TJLC fans resist the explicit denials of a queer identity by the creators, maintaining their own interpretation as the truth. Although to some extent, TJLC empowers producer authority, as fans wait patiently to be "proven right" and have their vision endorsed by Moffat, I believe that as long as they are directly resisting creator statements and calling for explicit queer acknowledgement, they inhabit a subversive space. TJLC, with their careful documentation on creator habits and BBC institutional reports, have turned the real world production of Sherlock into a text to be analyzed.

Some fans demonstrate their resistance by no longer approaching the producers for clarification or airing their concerns. These fans have shifted their efforts to an in-depth assessment of Moffat's works, producing critical analyses for the fandom at large in an effort to prompt further awareness and examination of how the producers deal with issues of gender and sexuality. They engage in substantial discussions surrounding the problems they see in his works. One such effort is found on the Tumblr blog, stfu-moffat. The description on the sidebar sets the blunt tone of the blog, "Because some people shouldn't be allowed to have their shit left unquestioned," insisting, "We don't hate DW or Sherlock, in fact we really really like those shows. That is why we're being critical. If we didn't like them, we wouldn't be nearly as annoyed, we'd simply change channels" (STFU STFU-Moffat "Moffat Issues"). Here, we find an active blog run by a team of moderators who have thoroughly examined and tagged their findings. They offer links to further follow 
discussion surrounding Doctor Who, Sherlock, and simply a "Moffat" link, to examine larger issues related directly to Moffat's writing. Here, they examine and field discussion from other readers about Moffat's works on topics from asexuality, bierasure, heterosexism, LGBT populations and queerbaiting. They support their analysis of the shows with Moffat's interviews to produce a thorough examination of how Moffat treats sexuality within his works, such as his fetishization of bisexuality, or his invalidation of Irene Adler's established lesbianism to turn her into a lovestruck damsel in distress for Holmes (STFU STFU-Moffat "Moffat Issues"). Sherlock fans are connecting their criticism of the show to larger cultural issues of sexuality and desire.

Sherlock and its producers name the elephant in the room, the homoeroticism that is currently masked under the label of 'bromance.' They are able to identify it because of their past experience and knowledge as fans themselves. However, as producers, they've taken pains to consolidate their authority, attempting to construct boundaries between themselves and current fan communities by claiming their non-involvement with Sherlock fandom and asserting that fan readings of the series as potentially queer are incorrect. This direct denial of fan perspectives and wishes creates an antagonistic relationship between fans and producers, where fans explicitly resist and question producer authority while producing their own truths. Sherlock producers do not hesitate to insist on their authority as creators/authors of the text. They unambiguously deny any mirroring of fan culture, while acting as unreliable narrators. This atmosphere of distrust and antagonism seems to encourage Sherlock fans' transformational activities. 


\subsection{Sherlock Fanfiction}

Sherlock fans encounter a text that is deliberately encoded with a homoerotic subtext, as well producers that intentionally mislead them. Additionally, fan attempts to perform as affirmational fans are routinely thwarted by producers. In the midst of all this, Sherlock fans have turned a considerable amount of attention on their fan efforts, such as fanfiction. Sherlock fans serve as an excellent example of transformative fans. They present an active reimagining of the canon that also displays a willingness to subvert societal norms of desire and sexuality.

As Derek Johnson notes, there is a "struggle to consensually legitimate competing knowledge claims about fans, cult texts, and their production... [which] operates discursively to constitute hegemonies within factionalized fan communities" (298). In other words, fans are constantly negotiating in their own works what will be considered hegemonic norms for the fandom. Reading, writing and recommending fanfiction is a staple fan activity, where fans explore different imaginings of the characters or plot in ways that may resist or reinforce producerly authority or hegemonic norms. By examining Sherlock fanfiction, I argue that we do find a resistant fan space, particularly in its embracing of non-normative sexuality and queer identities. Sherlock resists the culture of homonormativity found in Supernatural.

The Sherlock fan presence on Archive of Our Own is quite impressive. The fandom's dominant pairing of Sherlock Holmes/John Watson is the most popular slash pairing on the website, eclipsing the next popular pairing of Dean Winchester/Castiel by a substantial margin. At the time of writing, there are over 
35,000 works dedicated to Sherlock Holmes/John Watson in the Sherlock fandom on Archive of Our Own. In this section, I'll be examining the fanfiction produced by the fandom to demonstrate how fans construct subversively queer narratives of their own creation.

As before, I'm following Reid's method of selecting popular works that can be considered "representative rather than unique" to the community and Heinecken's method of examining the most popular or "widely recommended" stories. I've selected works of fanfiction that are representative of the Sherlock fan community and are among the most recommended (Heinecken 48; Reid 467). These are considered to be fandom "classics" and are often recommended by power fans within the community. Examining what the most popular and widely recommended stories are gives insight on what are acceptable and popular imaginings within the fan community. These fics can be considered representative of fan fiction in the fandom, particularly in the way that these works incorporate themes that are widely utilized in the fandom. The three works are considered long-form, ranging between 25,000-100,000 words long, they are "The Paradox Series" by wordstrings, "A Cure for Boredom" by emmagrant01, and "Two Coffees One Black One with Sugar Please" by Linpatootie.

In her work on darkfic Robin Reid notes how fanfiction in general moves across a "spectrum from imitation to transformation. Fan fictions, by their nature, are derived from a source text. While some authors strive to imitate key elements of the source, others engage in a range of transformations" (470). This is similar to the 
distinction between affirmational and transformative fans discussed earlier. Reid constructs a spectrum of fan works that largely remain within the canon and offer little variation to setting, characters, etc., and those which push to extremes, such as radically changing the plot or settings, or exploring different character nuances.

The Sherlock fandom classics perform the radical transformations that Reid discusses. While the Supernatural fanfiction is extremely homonormative, many of the Sherlock fanfictions create a much more queered space. Sherlock fanfiction often explicitly discusses hegemonic norms and then subverts them. Within the stories, Holmes and Watson avoid the language of "destiny" or fate that is so common within the Supernatural fan works. In Sherlock stories, desire is usually couched as a fixation, obsession, or even simply a need, rather than the romance of traditional slash. This formulation of desire has many different connotations that explore the complicated, messy aspects of attraction and desire. With this framing of desire, the relationship becomes less of a happily-ever-after romance and conjures up images of unhealthy relationships and questionable boundaries, associations that are on the darker side of romance. These themes, along with a focus on violence, are typical of darkfic. When writing from the lens of Holmes, fan writers render the familiar alien and encourage readers to scrutinize and question assumptions about love and relationships. Within fanfiction, writers also make use of Watson's traditional role as the audience/reader stand-in, providing a comfortable entry point for readers. Over the course of the story, this entry point is often challenged, either through adopting Holmes' perspective or complicating Watson's character beyond an 'everyman.' As Anne Jamison states, "at its best, the Sherlock fandom lives up to the 
literary promise of online fanfiction- consistently producing experiments in topic and form that a dedicated audience is willing to try and, often enough, embrace for the fresh perspectives and twists on beloved characters and scenes they offer" (55). With its incorporation of neuro-atypical identities, underrepresented queer identities like asexuality, and the queered performance of romance and intimacy, Sherlock fandom departs from producer-sanctioned interpretations to create a fresh interpretations and a resistant space for fans.

The Sherlock fanfiction often queers traditional slash staples. Mirna Cicioni speaks about the prevalence of "eroticization of nurturance" in slash stories, in which the partners take care of one another, such as when a partner is sick. Often, these situations serve as the moment when shared feelings are realized, or "represent protectiveness" between the pair (163). Cicioni argues that this nurturance, often including blankets and food, a symbol of shelter and sustenance, "are eroticized because they give a physical dimension to the closeness of the bond between the partners and lead to, or become a part of, an intimacy that also has a sexual component" (163). While nurturance is a theme in "The Paradox Series," it is amplified and distorted. Rather than foregrounding nurturance to create an idyllic love that's destined to be, fan author wordstrings has constructed a story where the relationship is not healthy and the romance is more of an obsession, where nurturance becomes fetishized and used to express a power dynamic.

"The Paradox Series" critically examines the norms of romance and socially acceptable expressions of emotion and desire. Wordstrings creates a Holmes who is 
much darker, drawn to violence and bodily functions, than the one found within the show. Referencing a flippant description of Holmes from the show wordstrings characterizes Holmes as a sociopath and characterizes Watson as a codependent who prefers a lack of control in his life.

The series begins with Holmes and Watson's first agreeing to be flatmates and follows the development of their relationship, personally and professionally, using the canon as a loose framework. The story depicts an extremely codependent relationship that is not entirely healthy for either participant. This Holmes possesses an unhealthy fixation on Watson, to which Watson not only doesn't object - but worries won't last, afraid that he will no longer be fascinating to the genius detective. He enjoys the menial tasks Holmes orders him to do, such as being called from across the flat to retrieve a phone that's across the room. Their codependence often puts Holmes and Watson in danger as Holmes seeks to try riskier behaviors with Watson, such as choking during sex, and deliberately irritating a wound during sex at a crime scene, but each character derives satisfaction from their dangerous behavior. The series alternates between the perspectives of Holmes and Watson, with a story that revolves around Holmes' attempt to be normal and "higher functioning" for Watson. In an attempt to find the line of acceptable desires for a partner, Holmes chronicles his desires for Watson and activities he wants to try into two lists, "Fine" and "Not Fine." He shares the list with Watson, his moral compass, who helps him re-categorize the lists from extreme behaviors such as swapping non-essential organs between their bodies to things as simple as divorce. Watson's work can be viewed as an extension of the nurturance Cicioni writes about, putting 
in the emotional labor to help Holmes understand the line between acceptable and unacceptable desires within their relationship.

The idea of the Fine and Not Fine lists are introduced early in the fanfiction series, as Holmes attempts to save Watson from Holmes' dark desires by persuading him to move out. He explains his inability to tell consistently the line between right and wrong, and tells Watson that that he wants Watson "possessed," fully at his mercy, unable to leave him (wordstrings "An Act of Charity"). Rather than being scared off, Watson offers to be Holmes' moral compass, setting up the driving goal of the series to achieve a balancing act between curbing the more dangerous and violent of Holmes' desires and yet remaining true to the thrill of danger that both enjoy in their lives.

The idea that the relationship is based on an unhealthy fixation is demonstrated repeatedly throughout the series, from Holmes' desire to microchip himself and Watson so he can constantly track their location, which is resoundingly rejected by Watson, to Holmes' unvoiced desire to swap non-essential organs, in order to achieve a symmetry and constant connection between them (wordstrings "New Days to Throw Your Chains Away"). The series reveals the layered powered dynamics at work in the generally simple action of caring for a loved one. When Watson becomes sick, he becomes totally dependent on Holmes' care. Watson contracts a particularly bad strain of the flu and doesn't want to go to the hospital, leaving Holmes to nurse the sick man in the meantime. This allows Holmes to view Watson's body ejecting fluids, running at a high temperature, and to satisfy his 
"scientific" curiosity. Watson becomes a science experiment, an object of affection to Holmes, who gets to see Watson pushed to bodily extremes such as high fevers and aches, leaking fluid through sweat and phlegm. Holmes is uncharacteristically considerate during the time, and reflects

What Sherlock admits to himself (he's ruthless) and John doesn't suppose (he isn't) is that all of this business is just about the headiest power trip Sherlock Holmes has ever been on. It's the bipolar opposite of charity. Sherlock feels like a god even more than is usual, and a god without a small, steady being to clear his throat and correct the sleuth's thinking from time to time. When he examines it ruthlessly (as is his habit), Sherlock adores being literally everything to his friend, and seemingly without any price tag involved in the selfish privilege. After all, John seems gradually to be mending, and Sherlock couldn't invent a virus which could have given him a better series of small, infinitely precious gifts. He loathes the suffering involved in John's ordeal and gladly would endure it himself if such were possible. But since it isn't...

It's all more or less spectacular. (wordstrings "A Thousand Threads of WhatMight-Have-Beens")

Holmes takes pleasure that he is the only one tending to Watson, being the sole means of support for the man. Holmes recognizes this tendency of his to isolate as Not Fine ${ }_{2}$ characteristic of abusive relationships that often intentionally isolate one partner from a support network to maintain dominance and control. The author highlights the isolation tactic as a hallmark of unhealthy, manipulative relationships through tags at the start of each installment. It's a status quo that is maintained throughout the piece. When Holmes reflects at the close of the story, "I can't think of how to love you without hurting you," Watson simply replies, "I don't give a flying fuck" (wordstrings "The Dying of the Bees"). Watson, with his own codependent issues, would prefer the pain that comes from a romantic relationship with Holmes 
as they negotiate a new script of what is considered a "normal" expression of desire and romance. This negotiation occurs through their re-sorting of Fine/Not Fine activities, and their own conditions to continue the relationship. They strike a balance between the extremes of Holmes' desires and Watson's passivity, and both choose to pursue their unconventional relationship of crime scene sex over a more traditional romance. This rejection of traditional romance, coupled with the deliberate subversion of slash staples such as the eroticization of nurturance, is one way that Sherlock fans construct a queered, resistant fan space.

"The Paradox Series" creates an interesting commentary on love, examining how love can be expressed in ways other than overt declarations. Love is touched on often in the story, but direct statements of "I love you" are rare; instead the characters call each other a "crime scene," harkening back to a past sexual encounter they shared at a crime scene, combining sexual intimacy and the thrill of danger both Holmes and Watson chase. Within "The Paradox Series," a controversial item on Holmes' Not Fine list is telling Watson "I love you" on the Perfect Day, or when they die. This means the simple phrase "I love you" becomes a loaded phrase that Watson fears (wordstrings "New Days to Throw Your Chains Away"; wordstrings "A Thousand Threads of What-Might-Have-Beens"). Here, love in the traditional sense is tied to a death. Explicitly, it's tied to the deaths of Watson and Holmes in the story, but it is also tied to the death of these characters' identities. For this Holmes and Watson, to abandon their non-normative desires and identities in favor of hegemonically endorsed expressions would be another kind of death of the self for them. As Anne Jamison notes, "In the fanfiction Sherlock inspires, the ins and 
outs of human relationship- of romance, whether sexual in nature or not- are defamiliarized by what amounts to Sherlock's outsider perspective" (56). wordstrings' “Paradox Series," similarly defamiliarizes how love and sexual desire is expressed. By creating a Holmes who is pronouncedly and explicitly sociopathic, a distance between the readers and the text is forced and readers must consider the depth of Holmes' fixation, begging the question of where the line is between romantic, sane practices and unhealthy obsession. The story creates a relationship between Holmes and Watson that is consensually supportive and within limits, mutually destructive, in contrast to the sanitized, incidentally gay sensibility of homonormativity.

Fan author wordstrings also removes Watson's everyman status to create a codependent, thrill-seeking man who enjoys a lack of control at times. Watson is no longer the safe entryway into Holmes' world, the function that he has historically served many times over in various reinterpretations of Sherlock Holmes' story. Readers are now confronted with Watson's deep codependency. Holmes is not the only person with unhealthy relationship habits; readers watch as Watson actively seeks out and encourages Holmes' fixation, from his initial offer to be Holmes' moral compass, to his 'gift' to Holmes where he hooked himself up to an EEG machine to allow Holmes to be 'inside' his brain. In this adaptation, even the morally upright Watson does not have a normative identity- he's drawn to Holmes' sociopathic behavior, and in his own addiction to "excitement," usually in the form of danger, are the seeds of another sociopath (Toadvine 60). Sherlock fanfiction is subverting 
not only traditional romance narratives in slash, but the structure surrounding Sherlock Holmes stories themselves.

In addition to subverting the traditional expressions of romance and emotion in slash fiction, the Sherlock fandom also brings their brand of subversion to sexual expression as well, exploring non-normative practices like BDSM and alternative sexualities and flouting hegemonic heteronormativity in the process. One of the most well-known pieces of fanfiction within the community is "A Cure for Boredom" by emmagrant01. In this story, Holmes decides to undertake an experiment testing Watson's responses to sexual arousal. Watson agrees to be in the experiment, but insists on honesty, as aside from establishing a safeword, Holmes did not explain the experiment to Watson at all. The experiment is conducted through a series of sexual encounters arranged by Holmes at a sex club.

The plot of "A Cure for Boredom," explores a wide range of sexual scenarios involving Watson, with Holmes always observing, but never participating. From threesomes with two women, with a heterosexual couple, to a dominatrix, and an encounter with a young gay man, the work chronicles a number of scenarios in the context of Holmes' experiment. There is a loosely-defined relationship between Holmes and Watson, who both understand that they're moving into an ambiguously gray area, not quite lovers, not simply friends.

As the work progresses, a dom/sub relationship becomes more and more apparent, where Holmes sets the boundaries and rules of each encounter, within the lines Watson's unwilling to cross. When Watson tries to rush into the next 
encounter planned by Holmes, Holmes stops him and reprimands him to think clearly and play by the rules of the encounter, or the experiment will end. The implication is that this tentative dom/sub relationship will also end. Rather than feeling irritated that he was "scolded," Watson instead "didn't feel angry at all. He felt an odd sort of relief to let it all go, to know that Sherlock was going to take care of it. Was going to take care of him" (emmagrant01). For Watson, this realization is a moment to reflect on how his relationship with Holmes has moved far from the norm of a flatmate or colleague, He has a dawning realization of the dom/sub dynamics that have developed between them rather being explicitly outlined, negotiated, and discussed as typical in most dom/sub relationships. Soon after his realization, both Holmes and Watson are encouraged (practically commanded) to have an open conversation about their own desire and needs in this relationship.

Later, after Watson decides at the last moment to safeword out of being penetrated by a male friend from the club, Holmes also names the dom/sub nature of the relationship. He agonizes, "It is my fault, John. I'm supposed to know what you want and what you don't. I'm supposed to pay attention to that, not put you in a position of having to safeword... My job in this is to take care of you. It's what a dom does and I failed completely" (emmagrant01). This particular statement provides an opportunity to reflect on the power relations on the dom/sub relationship. It's one of the first times the dom/sub dynamic is finally named, however Holmes' articulation of a dom's duties suggest that Watson, the sub in question, has limited choice or agency. It makes an assumption that a dom is supposed to be near omnipotent, anticipating the sub's needs and desires before they arise, allowing 
little room for spontaneity, exploration, or play. As Burr notes, some view the dom as a masculinized position. Holmes' words thus reinforce a male dominated sexuality (52). However, Holmes, in his expression of worry, exhibits vulnerability in his role as a dom. Conception of what a dom should do is incongruent with his own actions, thus suggesting that he is the one who is out of control, relying on the sub to ground the encounters and set the pace. His confession sparks a moment of honest, plain communication of desire between the two, forcing them to recognize and confess their romantic feelings. Typically in slash, sex follows the confession of feeling, but "A Cure for Boredom" plays with the slash formula in addition to sexuality, as there is no gay panic and the sexual intimacy actually comes before the development of romantic feelings.

Within the story, Holmes and Watson explicitly reject monogamy, embracing the ability to choose different sexual partners, as well as choosing to incorporate a dom/sub dynamic into their relationship. The concept of choice allows for a freedom that the homonormative "fate," does not, providing a wider possibilities of expressing sexual desire and romantic love. When Holmes encourages Watson to pick the subject of the next Holmes-crafted encounter, Watson at first picks his own targets, fulfilling the objectives set by Holmes. Both parties derive pleasure from Watson's activities outside of the relationship. For the last encounter, rather than picking another stranger at the club, Watson chooses to include Holmes, a first for the arrangement. At first, Holmes resists. He warns Watson, "I want to fucking own you. I want to see you do things you cannot possibly imagine... I want to do things to you, things that frighten me. I want to watch other people do things to you. I want to 
hurt you and..." His eyes locked on John's and he stopped. His face paled, as if he'd just realized he'd said those words out loud" (emmagrant01). Holmes' response minimizes Watson's capability to determine his own desire and set his own limits.

However, Holmes' words are a clear statement of desire, in which Holmes expresses and explicit interest in the sadistic play aspect of BDSM, which Watson accepts. This discussion of boundaries that is integral to not only dom/sub relationships, but any intimate relationship. It's an honest communication that addresses each other's needs. Holmes attempts to warn away Watson, arguing that Watson doesn't fully understand the request and wouldn't want it if he did. Here, Holmes is dismissing Watson's feedback, insisting that his own interpretation of Watson's arousal is more accurate than Watson's own stated feelings. Watson rebels, insisting on his choice for Holmes and declaring, "I may be a sub, but I'm not some fucking wilting flower. If I don't want to do something, you'll know. I invaded Afghanistan, remember? I can handle you, and I can kick your arse if I have to" (emmagrant01). Watson reasserts his power in the situation while invoking his newfound identity as a sub, reminding Holmes that he has choices and he needs to be able to articulate them. It reasserts the open communication of desire and reflects the power that subs do hold to set the pace and content within dom/sub relationships. For this Holmes and Watson, BDSM isn't pathologized, a condition that can be treated and the person rehabilitated to "normal" desires; instead, their participation in BDSM is entwined with their sexuality (Burr 55). 
In "A Cure for Boredom," the development and realization of a dom/sub dynamic isn't simply a means to an end (the end being a happily committed couple solving crime into the sunset) that is dropped the moment the goal is achieved. Vivien Burr notes that BDSM is still popularly represented as a deviant and perverted, and if a hero engages with it, they always have an "excuse" (56). Holmes and Watson's BDSM is not a "temporary pathology," they continue to navigate the subject of monogamy and further sex play (56). They decide on boundaries for the dom/sub aspect of the relationship. They decide that while "sharing" Watson is alright, and Holmes isn't interested in playing with other individuals, if either one of them change their mind in the future, they will discuss it. Watson notes,

It was incredibly freeing to think that this didn't have to be anything, didn't have to follow any prescribed pattern. They could make it whatever they wanted. God, the possibilities. He'd always thought he'd eventually meet a woman, get married, have children -- but there was no reason it had to be that way. The future seemed far more open right now than it had in a long time. Anything was possible. (emmagrant01)

Within "A Cure for Boredom," the payoff comes when both Holmes and Watson acknowledge their relationship, establish boundaries, and reaffirm the necessity of honesty. Jamison notes, "as a whole, Johnlock fic depicts long-term exclusivity in a complex light, and with an attention that much professionally produced culture seems to find impossible or unattractive" (62). Within the story, BDSM and nonmonogamous play can be part of a fulfilling emotionally exclusive relationship, and embracing that identity can be freeing. While this does place a primacy on the relationship between Holmes and Watson, it also removes the association of BDSM 
with "bad" or "evil" characters (Burr 55-56). The good guys can be happy and kinky too.

Rather than accepting the repeated denials of a romantic relationship between Holmes and Watson by the producers, some fans create fanfiction that seems to be speaking back to the queerbaiting tactics of Sherlock. In a marked departure from most slash fanfiction, which reflects a "gay panic" or struggles with the idea of coming out, Sherlock fanfiction actively debates the boundaries of identity and sexual labels. The fan fiction contrasts the unwillingness to utilize a label of queer or gay with the need for a clear, stated identity with which to be 'out'. “Two Coffees One Black One with Sugar Please" uses an experiment-driven plot again, this time to examine whether or not sharing a bed with another person improves one's sleep. Watson reluctantly agrees to participate, persuaded by the short window of time proposed. However, the initial two weeks turns into a month, which bleeds into three months. The story traces the development between Holmes and Watson as they move from friends and flat mates into lovers into a public relationship. With such a contained focus, the process involved in identity development and naming becomes the driving force of the plot.

"Two Coffees," plays out the debate between Moffat's unwillingness to name a sexual identity for Holmes and the critics of queerbaiting who call for explicit queer representation. At the three month mark, Watson becomes particularly concerned with how they're "blurring the boundaries of friendship" now that the experiment has become habit, and he insists on talking about it while Holmes is less 
interested (Linpatootie "An Epiphany Is Just a Fancy Way of Realising You're an Idiot"). Watson blurts out the root of the problem, insisting that he is not gay. Holmes becomes irritated and launches into a tirade about Waton's reticence
"What's that got to do with anything?!" he exclaims, frustration sharp on his tongue. "Every time someone as much as hints at - at something, between us, you whip that out and hold it in front of you like some kind of shield and what does it matter? Everybody knows you're not gay, John, you love women, you drool yourself into a massive puddle every time an appealing one walks past, but why on earth does that exclude... - does that mean you can't... - it's almost offensive, it is [...]This, this, whatever it is," Sherlock continues, waving his hand between the two of them, "Why do you need to do that, to backtrack like that, because I happen to have a penis? It's ridiculous. It's. It makes me angry. We're sharing a bed, it's not like I'm proposing marriage or forcing you into a Pride parade." (Linpatootie "An Epiphany Is Just a Fancy Way of Realising You're an Idiot")

Keeping in mind the show's propensity to joke about the assumption that Holmes and Watson are gay, this moment becomes particularly interesting. Within the context of the story, Holmes rejects the knee-jerk habit of labeling and classifying. Watson insists that naming is important, working to find a definitive label instead of being satisfied with the "blurring of boundaries" as Holmes is (Linpatootie "An Epiphany Is Just a Fancy Way of Realising You're an Idiot"). Both responses are notable and important. Watson's need for a clear, stated label and a word for his evolving identity is strikingly similar to critics of queerbaiting, while Holmes can be read as an attempting to opt out of binary heterosexual/homosexual labels. He can also be read as the personification of producers who are unwilling to seriously address the homoerotic subtext. That Watson and Holmes ultimately make a public 
declaration of same-sex attraction and their relationship via Watson's blog is a triumph for those calling for explicit representation.

While Sherlock producers are avoiding the "agenda" of sexuality, many fans are not- exploring lesser-known identities under the queer umbrella, such as asexuality. Sexual intimacy or lack thereof is a topic that Sherlock fanfiction discusses regularly. Once the two characters in "Two Coffees" declare their feelings, the topic of sex arises. Watson points out that he wasn't quite sure of Holmes' feelings on the matter; “You told me you weren't curious enough to do something about it." Holmes replies "That was then... This is now... I'd do it for you, if you wanted, anyway" (Linpatootie "Crocodiles and Cannibals and Putting Things in Sherlock's Hair"). The implication is that Sherlock hasn't been and generally isn't interested in having sex, a characterization that is also invoked in "The Paradox Series," as "John knows that Sherlock's sex drive outside of the Object of Admiration is both practically nil and theoretically nonexistent" (wordstrings "New Days to Throw Your Chains Away"). In these stories, Holmes does find enjoyment in the sexual encounters, but the stories incorporate themes of asexuality, pointing out Holmes' contentment with a relationship devoid of physical intimacy. Within the Sherlock fandom, asexuality remains a possibility for a character within the main pairing of the fandom. While the percentage of fanfiction that features an asexual Holmes is a small portion of the staggering amount of Sherlock Holmes/John Watson stories, the Sherlock stories account for nearly $40 \%$ of all asexuality-related fanfiction on Archive of Our Own, well over 600 works contributing to the tag (DestinationToast) and constitute by far the single biggest tag on the archive. The 
willingness to incorporate asexuality into some fan imaginings, and the fact that it is often presented as a valid possibility for a main character in a popular fan pairing is another demonstration of the Sherlock fandom's willingness to talk about layers of identity and devote space to debating and discussing lines and boundaries of identity and relationships.

In addition to Sherlock's fanfiction being an excellent example of the transformative possibilities of fanfiction and works in general, I believe that Sherlock's fanfiction constructs an actively queered, subversive space that resists traditional romance and homonormativity through its thoughtful engagement with BDSM themes, incorporation of asexuality, and exploration of neuro-atypical character identities. Even in the fandom classics examined here, which contain less radical themes than found elsewhere within the fandom, the stories still incorporate ideas of BDSM and asexuality and discussions of identity in ways that subvert and resist the homonormativity implied by the "bromantic" approach of the series and its producers. 


\section{KEEPING THEM TALKING}

As noted by Chin, "fandom is wrought with tension [and] the fans' status quo is often challenged" (98). With the rise of social media, the producers, authors, and creators of TV shows are easier to reach than ever before, and thus the status quo of fandom is constantly negotiated. While some fans make their own queer readings of the texts, many others adhere to producer authority. There is a "growing relationship between producers and fan collaborators, whereby some fans are no longer resisting being co-opted (unofficially) into the industry" (Chin 98). The power dynamics between fan resistance and the ever-increasing presence of producer authority are a new arena to consider in fan studies. Here, I've worked to outline two emerging communication practices and fan cultures: collaborative nature of Supernatural's collaborative producer-fan relationship and the antagonistic relationship between producers and fans of Sherlock.

What I've argued then, is that producers of both Supernatural and Sherlock have knowingly encoded their shows with a queer subtext. Queerbaiting allows producers to "attract as wide a range of audiences as possible" (Sender 305). However, this is not done solely to appeal to queer-identified viewers, but also because of the ever-increasing fan activity. Fandom is no longer a community on the margins, but a "niche market" increasingly being targeted by marketers. Fandom is 
becoming mainstreamed and fan activities like slash are progressively better known. Gone are the days when potential slash fans had to be vetted and tested before being told about or offered slash. As sites like Tumblr and Archive of Our Own gain popularity, fan activities are being made more transparent. More than simply wanting to expand their audience and attract queer viewers, producers of Supernatural and Sherlock are creating their product with these "niche markets/cult audiences" in mind (Hills 36). The producers of Supernatural have cultivated a "model of dedicated and loyal consumers" who have saved a show that seemed doomed to cancellation at the start of season four (Hills 36). Moffat and Gatiss have done the same, embracing a transmedia paradigm (Jenkins, Ford and Green 152) and utilizing their own past knowledge as fans to create hyperdiegetic texts that draw in audiences.

Supernatural's producers have embraced an apparently open relationship with fans, treating them as collaborators while rewarding affirmational fans who seek to stay in the producers' good graces. Their concerted effort to participate in fan spaces and dialogues, especially on social media, and their repeated references to fandom within the canon and at conventions cultivate a sense of collaboration and closeness. Their use of \#SPNFamily positions fans as peers and important people, not mindless audiences to which to pander. While they mirror some "resistant" fan activities by creating a queer subtext and alluding to slash, their mirroring actually sanctions only certain kinds of fans. In this way, "initially unexpected consumption practices, far from challenging the interests of TV producers, and the power relationships through which capital circulates, are rapidly 
recuperated within discourses and practices of marketing" (36). As producers sanction and celebrate certain fan activities or interpretations, fans are encouraged to adopt an affirmational role. These affirmational fans further write fictions that, while exploring narratives of same-sex desire, cannot be considered queer, or truly subversive. Supernatural slash has a tendency to fetishize gay male sexuality, replicating standard romance narratives and generally displaying homonormative values that turn queer male sexuality into an object to be looked at and consumed. The producers of Sherlock, in contrast, have utilized a very different tactic in their interactions with fans. They have developed an antagonistic relationship with fans, explicitly denying fan interpretations and consolidating their own producerly authority over the text. Their communication style as producers works to further protect and reinforce their own authority, creating distinct lines between themselves as producers and their fans (while simultaneously laying claim to a fan identity for themselves). The producers have repeatedly demonstrated themselves to be unreliable narrators, effectively barring Sherlock fans from fulfilling the duties required of affirmational fans. Sherlock fans overwhelmingly turn to transformative efforts, expanding their works to examine and subvert larger societal questions of sexuality, desire, and identity. These works explore identities such as BDSM and asexuality, working on larger transformative efforts regarding sexuality. However, this is still transformative within limits, as noted previously within academia, this work is largely being done by heterosexual women (Bacon-Smith Enterprising Women: Television Fandom and the Creation of Popular Myth; Bury; Green, Jenkins and Jenkins; Jenkins). While slash is not accepted by Sherlock's producers, fans do 
not hesitate to speculate or confront the show's producers regarding slash shipping. In the absence of producer participation in Sherlock fan spaces, Sherlock fans avoid the in-depth "policing of fan material by the commercial industry" (Jenkins, Ford and Green 150). The fan works produced within Sherlock fan communities emphasize queerness as opposed to normativity, as called for by Reid (480), and counter producer visions of the show.

Comparing the fan cultures of Supernatural and Sherlock side by side helps to expose some of the potential impact of different styles of producer/fan interactions in the age of social media and "niche marketing" (Hills 36). Supernatural producers have embraced social media and fan spaces, consistently and repeatedly, engaging with fans not only at special events, but from weekly live-tweeting sessions and casual conversation. At the same time they sanction affirmational fans who are willing to be content with producers' queerbaiting. While Supernatural fans continue to write slash stories, their slash conforms to heteronormative ideology. Sherlock, conversely, has largely limited producer interactions with fans. While the Sherlock producers also focus on transmedia engagement and try to encourage affirmational fan activities, their direct refusal of transformational fan readings inspires fan resistance. With this enforced distance between fans and producers, Sherlock has seen a flourishing of transformative efforts and work by its fans.

As stated previously, this project is not intended to argue a causal relationship between producer-fan interactions and the fictions produced by fan communities. Rather, it points to the different kinds of fan cultures being cultivated in today's world of fandom. Further, it explores the holistic world of the fan today, 
taking into account not only the text but the hyperdiegetic text and fan-produced narratives as well. In this project, I've demonstrated different communications styles that have developed between fans and producers, as well as the wildly fan cultures that have developed. This project not only interrogates media queerbaiting and the idea that all slash activities are necessarily resistant, but suggests that fans who feel themselves to be "shut out" by producers may be more likely to confront producers and create transformative stories than fans who perceive themselves to be in a more collaborative relationship with producers.

However, some recent developments indicate that the relationship between Supernatural fans and producers is changing and that fans are beginning to confront more directly producers' queerbaiting strategies. Supernatural fans are starting to call out en masse the show's enormous queerbaiting problem, among other criticisms of misogyny and stunning lack of minority representation (Romano "'Supernatural' Fandom Gives the Cw a Lesson in Twitter Pr"). As a promotion for the San Diego Comic Con after the close of season 9 and thus after the investigative frame of this study, the CW launched a Twitter hashtag to encourage fans to submit questions the cast and crew that would be answered at Comic Con. \#AskSupernatural was flooded with fan critiques of the show's misogynistic treatment of women, lack of people of color, as well as critiques of the queerbaiting that has characterized Supernatural throughout its run (Romano "'Supernatural' Fandom Gives the Cw a Lesson in Twitter Pr"). It seems that Supernatural fans are beginning to demand a level of accountability from the show. 
Many fans in the \#AskSupernatural tag raised questions of race. Both Supernatural and Sherlock both have a significant lack of characters of color. Supernatural has steadily lost many of their reoccurring characters of color, and Sherlock, aside from reoccurring role of Sally Donovan, has no characters of color. Neither text deals with race in a substantive manner. This lack of engagement is reflected within the fan works. With race being largely absent within the text, fans continue that absence in their works. Similarly, class, another feminist concern, isn't addressed beyond a passing mention in either Supernatural or Sherlock. Both shows establish the class status of the characters in their first episodes. While at times both shows explore conflicts related to money, these conflicts are always relatively easily solved within an episode. Class remains unaddressed in the fan works as well, as fans focus on other conflicts and plot developments to advance their story.

Future research might examine this change in fan behavior and whether it is connected to changes in producer/fan relationships. Why are Supernatural fans beginning to assert their authority over the text now, after years of being willing to tolerate producers' queerbaiting? Is this recent, more direct resistance on the part of Supernatural fans a sign that there is a limit to producers' ability to cultivate affirmational fans? Are producers' attempts to sanction particular fan behaviors no longer effective in silencing fans who wish to maintain a collaborative relationship with producers?

Further research could also investigate fan organizing and advocacy to producers, specifically surrounding issues of identity, including race, gender, and sexuality. As fans are becoming increasingly visible, many are becoming more vocal 
and unwilling to sit idly as the shows to which they feel connected to mock, erase, or otherwise dismiss marginalized identities-identities that increasingly fans may share as producers work to expand audiences into segments like LGBTQ populations.

Ultimately, fandom is evolving and will continue to do so. If this trend continues, we can expect to see more and more producers utilizing fan tactics to cultivate a wider audience. Fans will navigate the ever-increasing producer presence, and carve out spaces for their own creative expression. Whether those spaces will be subversive queer transformations or homonormative affirmations remains to be seen. 


\section{REFERENCES}

"About the Otw." Organization for Transformative Works. Web2014.

"Are You There God? It's Me, Dean Winchester." Supernatural: CW, 25 Sept 2008.

"The Blind Banker." Sherlock: BBC, 1 Aug 2010.

"Death Takes a Holiday." Supernatural: CW, 12 Mar 2009.

"Goodbye, Stranger." Supernatural: CW, 23 Mar 2013.

"The Great Game." Sherlock: BBC, 8 Aug 2010.

"Heaven and Hell." Supernatural: CW, 20 Nov 2008.

"His Last Vow." Sherlock: BBC, 12 Jan 2014.

"The Hounds of Baskerville." Sherlock: BBC, 8 Jan 2012.

"It's the Great Pumpkin, Sam Winchester." Supernatural: CW, 30 Oct 2008.

"The Man Who Would Be King." Supernatural: CW, 6 May 2011.

"My Heart Will Go On." Supernatural: CW, 15 Apr 2011.

"Pilot." Supernatural: CW, 13 Sept 2005.

"Point of No Return." Supernatural: CW, 25 Apr 2010.

"Reading Is Fundamental." Supernatural: CW, 4 May 2012.

"Route 666." Supernatural: CW, 31 Jan 2006.

"The Sign of Three." Sherlock: BBC, 5 Jan 2014.

"A Study in Pink." Sherlock: BBC, 25 July 2012.

"Survival of the Fittest." Supernatural: CW, 18 May 2012.

"Swan Song." Supernatural: CW, 13 May 2010.

"The Third Man." Supernatural: CW, 8 Oct 2010.

"What's up, Tiger Mommy?" Supernatural: CW, 10 Oct 2012.

Åström, Berit. "' Let's Get Those Winchesters Pregnant": Male Pregnancy in"

Supernatural" Fan Fiction." Transformative Works and Cultures 4 (2010).

Print.

Bacon-Smith, Camille. Enterprising Women: Television Fandom and the Creation of Popular Myth. University of Pennsylvania Press, 1992. Print.

---. "Spock among the Women." The New York Times Book Review 16 (1986). Print.

Baker-Whitelaw, Gavia. "Why Steven Moffat Rules Tumblr Fandom." The Daily Dot 29 Mar 2013 2013. Print.

Burr, Vivien. "Bad Girls Like It Rough: Bdsm in Buffy the Vampire Slayer." Praxis 18.1 (2006): 45-57. Print.

Bury, Rhiannon. Cyberspaces of Their Own: Female Fandoms Online. Vol. 25: Peter Lang, 2005. Print.

Chin, Bertha. "The Fan-Media Producer Collaboration." Science Fiction Film \& Television 6.1 (2013): 87-99. Print. 
Cicioni, Mirna. "Male Pair-Bonds and Female Desire in Fan Slash Writing." Theorizing fandom: Fans, subculture and identity (1998): 153-77. Print. cloudyjenn. "The Mirror." The Mirror. Fanfiction.net 1 Mar 2011 2011. Web. Company, The Nielsen. "Living Social: How Second Screens Are Helping Tv Make Fans." 8/4/2014 2014. Web. 8/29/2014 2014.

DestinationToast, Strangelock, and Penns-woods. "221b Con Fandom Stats Slides: Master Post." Destination: Toast! April 2014 2014. Web.

Dhaenens, Frederik, Sofie Van Bauwel, and Daniel Biltereyst. "Slashing the Fiction of Queer Theory: Slash Fiction, Queer Reading, and Transgressing the Boundaries of Screen Studies, Representations, and Audiences." Journal of Communication Inquiry (2008): 335-47. Print.

Duggan, Lisa. The Twilight of Equality? Neoliberalism, Cultural Politics, and the Attack on Democracy. Boston: Beacon Press, 2003. Print.

emmagrant01. A Cure for Boredom. ArchiveOfOurOwn.org 28 Mar 20122012. Web2014.

Falzone, PJ. "The Final Frontier Is Queer: Aberrancy, Archetype and Audience Generated Folklore in K/S Slashfiction." Western folklore (2005): 243-61. Print.

Forster, Peter. "Rad Bromance (or I Love You, Man, but We Won't Be Humping on Humpday)." Reading the Bromance: Homosocial Relationships in Film and Television. Vol., 2014. 191. Web.

Goldman, Eric. "New Supernatural Showrunner on His Plans for Season 8." Ziff Davis LLC 2012. Web. 10 May 2015.

Gómez, John M. "Erotic Cello in Art, Film and Literature." 30 Sept 2014 2014. Web. Green, Shoshanna, Cynthia Jenkins, and Henry Jenkins, eds. Normal Female Interest in Men Bonking: Selections from 'the Terra Nostra Underground'and 'Strange Bedfellows'. 1998. Print.

Harvey, Chris. "'Moriarty Is Dead... But I'm a Liar' - Why We Just Can't Trust Sherlock's Writer." The Telegraph 13 Jan 2014 Print.

Heinecken, Dawn. "'I Wasn't Planning on Hurting You- Much": Sadomasochism, Melodrama and "Buffy the Vampire Slayer" Fan Fiction." Spectator 25.1 (2005): 48-60. Print.

Hills, Matthew. Fan Cultures. Routledge, 2003. Print.

Hunting, Kyra. "" Queer as Folk" and the Trouble with Slash." Transformative Works and Cultures 11 (2012). Print.

Ittner, Phil. "Interview: Sherlock Creators Give Clues to Holmes' Enduring Appeal." Al Jazeera America 19 Jan 2014 2014. Print.

Jamison, Anne. Fic: Why Fanfiction Is Taking over the World. BenBella Books, Inc., 2013. Print.

Jeffries, Stuart. "'There Is a Clue Everybody's Missed': Sherlock Writer Steven Moffat Interviewed." The Guardian 20 Jan 2012 2012. Print.

Jenkins, Henry. Textual Poachers: Television Fans and Participatory Culture. London: Routledge, 1992. Print.

Jenkins, Henry, Sam Ford, and Joshua Green. Spreadable Media: Creating Value and Meaning in a Networked Culture. NYU Press, 2013. Print. 
Johnson, Derek. "Fan-Tagonism: Factions, Institutions, and Constitutive Hegemonies of Fandom." Fandom: Identities and communities in a mediated world (2007): 285-300. Print.

K., Veronica. "Supernatural - 9.07 - Dean and Castiel's Reunion and Queer-Baiting." 20 Sept 2013 2013. Web.

katiuska2h. "8x13 Commentary: The Dean - Aaron Pub Scene." YouTube 14 Sept 2013. Web. 16 Jan 2015.

Lavigne, Carlen. "The Noble Bachelor and the Crooked Man." Sherlock Holmes for the 21st Century: Essays on New Adaptations (2012): 13-23. Print.

Linpatootie. "Crocodiles and Cannibals and Putting Things in Sherlock's Hair." Two Coffees One Black One With Sugar Please. ArchiveOfOurOwn.org 25 Mar 2012 2012. Web2014.

---. "An Epiphany Is Just a Fancy Way of Realising You're an Idiot." Two Coffees One Black One With Sugar Please. ArchiveOfOurOwn.org 12 Mar 20122012. Web2014.

loudest-subtext-in-television. "Softly, Softly: The Bbc's 2009 Lgb Research Commission and the Johnlock Conspiracy." Sherlock: Loudest Subtext in Television 19 Jun 2014 2014. Web.

Martin, Dan. "Doctor Who - Let's Kill Hitler: Viewers Are in for a Real Treat." The Guardian: TV and Radio Blog 2011 Web.

Mellor, Louisa. "Sherlock: His Last Vow Q\&a with Steven Moffat, Amanda Abbington, Lars Mikkelsen \& More..." Den of Geek! 5 Feb 2014 2014. Web.

Milner, Ryan M. "Working for the Text Fan Labor and the New Organization." International Journal of Cultural Studies 12.5 (2009): 491-508. Print.

Murray, Simone. "'Celebrating the Story the Way It Is': Cultural Studies, Corporate Media and the Contested Utility of Fandom." Continuum: Journal of media \& cultural studies 18.1 (2004): 7-25. Print.

obsession_inc. "Affirmational Fandom Vs. Transformative Fandom." obsession_inc 2009 Web.

Obstinatrix. "Author Spotlight: Obstinatrix." Destiel Fanfiction. 8 Nov 20142014. Web.

---. "[Masterpost] Our Bodies, Possessed by Light ". if your life is burning well, poetry is just the ash. 2 Oct 20112011 . Web.

Padalecki, Carol. "Girl Ask Jensen Ackles About Fanfictions (Legendado)." YouTube 2009. Web.

Pantozzi, Jill. "Steven Moffat Condescends to Explain That Huge Doctor Who Plot Hole About the Ponds." The Mary Sue 2013. Web. 9/10/14.

pyjamagurl. "The Day the World Went Away--Master Post." INSEYBURGULAR: for the sake of your wolflihood... 6 Oct 20102010 . Web.

Redcoast. "Damon Lindelof Was Right." 2013. Web.

Reid, Robin Anne. "Thrusts in the Dark: Slashers' Queer Practices." Extrapolation 50.3 (2009): 463-83. Print.

Romano, Aja. "How One Question Triggered a "Supernatural" Fandom Meltdown." The Daily Dot 6 May 2013 2013. Print.

---. "'Supernatural' Fandom Gives the Cw a Lesson in Twitter Pr." The Daily Dot 17 Jul 2014 2014. Print. 
Rosenberg, Alyssa. "Steven Moffat on 'Sherlock's Return, the Holmes-Watson Love Story, and Updating the First Supervillain." Interview. Think Progress 7 May 2012 2012. Print.

Sender, Katherine. "Selling Sexual Subjectivities: Audiences Respond to Gay Window Advertising." Critical Studies in Media Communication 16.2 (1999): 172-96. Print.

Sharma, Rekha. "Community Clip Show: Examining the Recursive Collaboration between Producers and Viewers of a Postmodern Sitcom." The Journal of Fandom Studies 1.2 (2013): 183-99. Print.

Shefrin, Elana. "Lord of the Rings, Star Wars, and Participatory Fandom: Mapping New Congruencies between the Internet and Media Entertainment Culture." Critical Studies in Media Communication 21.3 (2004): 261-81. Print.

Smith, Aidan. "Time Lad Scores with Sex and Daleks." The Scotsman 6/6/2004 2004. Print.

Spelling, Ian. "'Supernatural' Actor Misha Collins Is the New Angel on the Block." Reading Eagle 14 Dec 2008 2008. Print.

Stars, 24Shining. "Full Video: Mark Gatiss at Mumbai Film and Comic Con 2014." YouTube 2014. Web.

STFU-Moffat. "Let's Look at the Twitter Thing from the Beginning." STFU Moffat. 22 May 2012 Web.

---. "Moffat Issues." STFU Moffat 2015. Web.

Thompson, Robbie. "@Greensiebeans He Did. And Yeah, I Think He Made the Right Call \#Supernatural." Web.

Toadvine, April. "The Watson Effect: Civilizing the Sociopath." Sherlock Holmes for the 21st Century: Essays on New Adaptations (2012): 48-64. Print.

Viva, Sensazione. "Steven Moffat Talk About Johnlock and Season 3 \& 4." YouTube 13 May 2013 2013. Web.

Williams, Don. "Creator Eric Kripke Talks 'Supernatural' Season 4." 08 Sept 2008 2008. Web.

Williams, Rebecca. "Good Neighbours? Fan/Producer Relationships and the Broadcasting Field." Continuum: Journal of Media \& Cultural Studies 24.2 (2010): 279-89. Print.

Woledge, Elizabeth. "From Slash to the Mainstream: Female Writers and Gender Blending Men." Extrapolation 46.1 (2005): 50-65. Print.

wordstrings. "An Act of Charity." The Paradox Series. ArchiveOfOurOwn.org 5 Nov 2012 2012. Web2014.

---. "The Dying of the Bees." The Paradox Series. ArchiveOfOurOwn.org 15 Nov 2012 2012. Web.

---. "New Days to Throw Your Chains Away." The Paradox Series. ArchiveOfOurOwn.org 2012. Web2014.

---. "A Thousand Threads of What-Might-Have-Beens." The Paradox Series. ArchiveOfOurOwn.org 6 Nov 2012 2012. Web2014. 


\section{CURRICULUM VITA}

NAME: $\quad$ Cassandra M. Collier

ADDRESS: Women's and Gender Studies Department

Stevenson Hall 320

University of Louisville

Louisville, Kentucky 40292

DOB: $\quad$ Springfield, Ohio - July $19^{\text {th }}, 1990$

EDUCATION

\& TRAINING: $\quad$ B.A., Women's, Gender, and Sexuality Studies and Theatre Bowling Green State University

2008-2012

M.A., Women's and Gender Studies

University of Louisville

2013-2015

AWARDS \&

HONORS:

Lilialyce Akers Graduate Assistantship in Community

Engagement, University of Louisville 2014-2015

RESEARCH \&

CONFERENCE

PRESENTATIONS:

"'Now People Will Definitely Talk:' Examining the resistant practices of the Sherlock fandom" Popular Culture Association / American Culture Association

Annual Conference, New Orleans, LA, Apr 1-4, 2015

"Check Your Tags: The Revolutionary Way Tumblr

Redefines Online Feminist Discourse and Activism,"

National Women's Studies Association Annual

Conference, San Juan, PR, Nov 13-16, 2014 
“'A More Profound Bond:' The homonormative nature of Supernatural and its fandom" Popular Culture Association in the South / American Culture Associate in the South Annual Conference, New Orleans, LA, Oct 24,2014

"Initializing Scan: Reading the Cyborg into Resident Evil" Popular Culture Association in the South / American Culture Associate in the South Annual Conference, New Orleans, LA, Oct 2-4, 2014

"The Year of Cultural Appropriation: Live Performances and Digital Responses" Co-author. Pennsylvania State University Women's and Gender Studies Graduate Organization Annual Conference, State College, PA, April 5, 2014

"In Need of a +1 : Female Worth in Bridesmaids," Women's Studies Research Symposium, Bowling Green State University, Bowling Green, OH, Mar 30, 2012

"More Than a Stage: Ripple Effects of the Living Theatre Company," Poster Presentation, Presidential Inauguration Student Research Symposium, Bowling Green State University, Bowling Green, OH, Nov 30, 2011 